THE GROWTH OF THE BODY AND ORGANS OF THE ALBINO RAT AS AFFECTED BY FEEDING VARIOUS DUCTLESS GLANDS (THYROID, THYMUS, HYPOPHYSIS AND PINEAL)

BY

E. R. HOSKINS

Institute of Anatomy, University of Minnesota

A thesis submitted to the faculty of the graduate school of the University of Minnesota in partial fulfilment of the requirements for the degree of Doctor of Philosophy

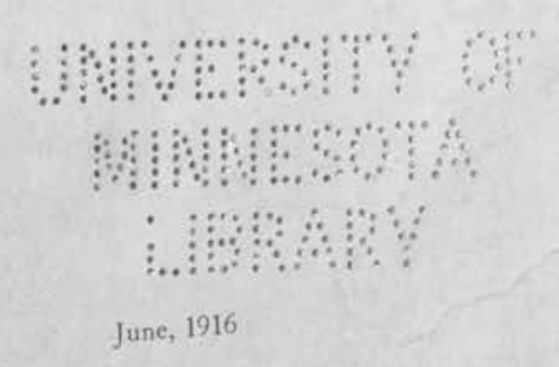




\section{ERRATA}

The Journal of Experimental Zoölogy, volume 21, number 3, October, 1916. The chart on page 307 (E. R. Hoskins) is Chart 3 and belongs on page 311. The chart on page 311 is Chart 1 and belongs on page 307 . The description of Chart 1 on page 307 refers to the chart on page 311 , and the description of Chart 3 on page 311 refers to the chart on page 307. This slip should be pasted on page 307 when the volume is bound. 
Reprinted from The Jovrnat of Experimental. Zoŏtogr, Vot. 21, No. 3 October, 1916

\title{
THE GROWTH OF THE BODY AND ORGANS OF THE ALBINO RAT AS AFFECTED BY FEEDING VARIOUS DUCTLESS GLANDS (THYROID, THYMUS, HYPOPH- YSIS, AND PINEAL).
}

\author{
E. R. HOSKINS \\ Institute of Anatomy, University of Minnesota
}

FOUR CHARTS

CONTENTS

296

297

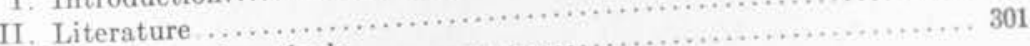

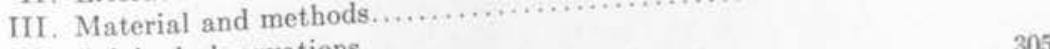

IV. Original observations, Weight and length..................... 305

1. Body as a whole. Weight and length norms............... 305

a. Comparison of controls with pineal feeding.. 310

b. Effects of thyroid, thymus, hypophysis and pineal feedine. 316

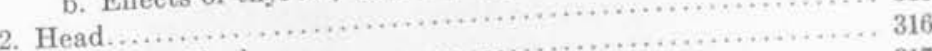

3. Eviscerated body ......................................... 317

4. Integument ..................................... 317

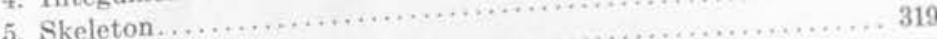

6. Brain 320

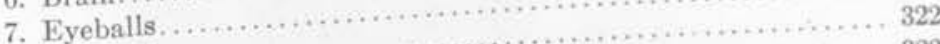

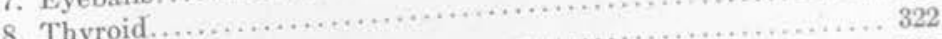

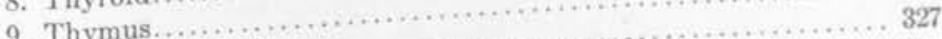

10. Heart. 328

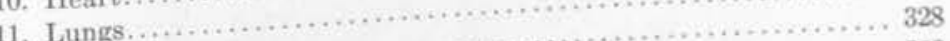

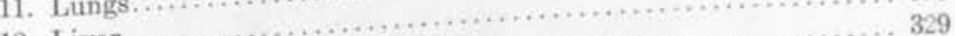

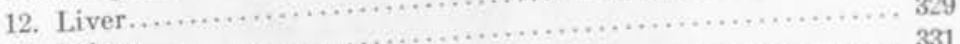

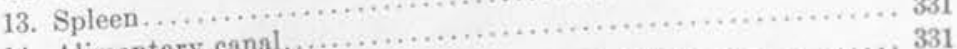

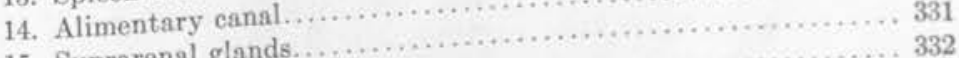

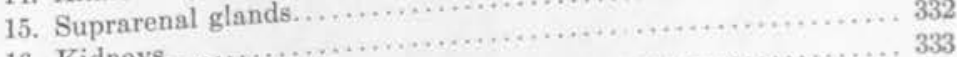

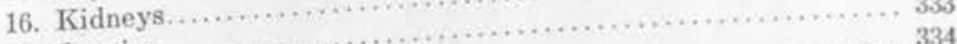

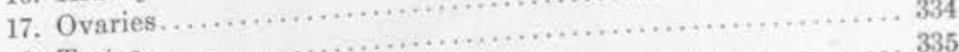

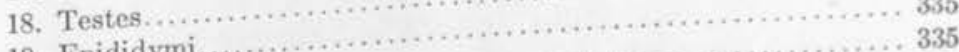

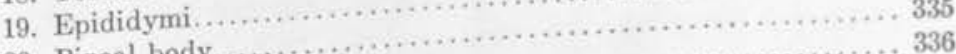

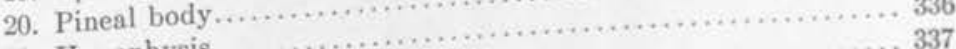

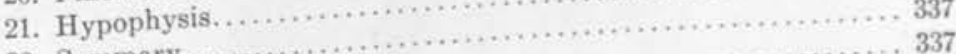

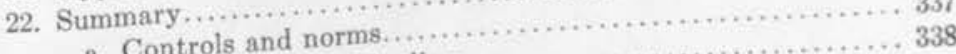

a. Controls and norms feeding ............................

295

octossR, 1916 


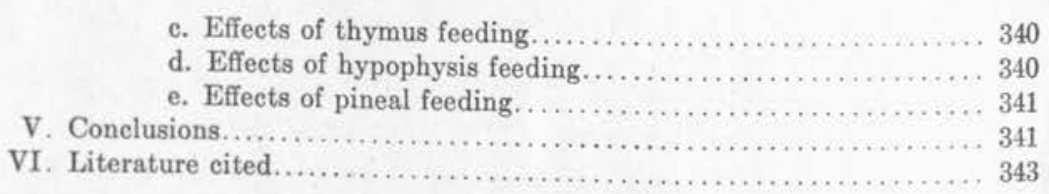

\section{INTRODUCTION}

The present investigation was undertaken in the hope of throwing further light upon the relations of some of the ductless glands to the growth process in albino rats. During the experiment it became evident that the growth rate in the control rats was in many cases somewhat different from that which has been generally described as normal, so it became necessary to include incidentally the question of the normal growth rate.

The investigation was carried on in the Anatomical Institute of the University of Minnesota, under the direction of Professor C. M. Jackson, to whom my grateful thanks are due for his constant interest in the work and his many very helpful suggestions.

Since the ductless or endocrinous glands were first recognized anatomically, various methods have been applied in investigating their functional significance. The four most commonly used, are extirpation of the glands, their transplantation, injection of their extracts and the feeding of the glandular substances.

Feeding ductless glands in order to study the effects of the hyperactivity thus possibly produced has certain objections. The absorption is slower than when injections are made, and the danger of infection is lessened; but the substances fed may undergo digestive changes in the alimentary tract. That the active principles of the ductless glands are not necessarily destroyed by digestion, however, is proven by abundant experimental and clinical results (Gudernatsch '12, and Abderhalden ' 15 especially in thyroid feeding). The feeding method was
selected for the present investigation. 


\section{LITERATURE}

A general discussion of the literature of all of the ductless glands is given by Vincent ('12), "Internal Secretion and the Ductless Glands," and in the more extensive work of Biedl ('13), "Innere Sekretion." The hypophysis literature has been reviewed by Cushing ('12). "The Pituitary Body and its Disorders:" and the work on the thymus has been considered recently by Basch ('13), "Beiträge zur Physiologie und Pathologie der Thymus." A complete list of references to work done upon the albino rat is given by Donaldson '(15).

A preliminary report of the principal results of the present investigation has already been published (Hoskins '16).

\section{Thyroid experiments}

Iscovesco ('13) found that daily injections of thyroid extract stimulated growth slightly in young animals but decreased the weight of old animals. He found nearly 100 per cent hypertrophy (measured in grams per kilogram body weight) in various viscera. The extreme and uniform hypertrophy of the organs and especially that of the uterus is difficult to understand. The fact that the liver and the female kidney show no overgrowth is remarkable.

Magnus-Levy ('95) found that feeding thyroid may cause loss in weight in an animal.

Cunningham ('98) fed 'considerable amounts' of thyroid to various animals without noting any toxic effects.

Moussu ('99) reported that small doses of thyroid stimulate the rate of growth in young dogs, but that large doses are toxic.

Rudinger, Falta and Eppinger ('08) and Kostlivy ('10) found that feeding thyroid stimulates the suprarenal glands.

Bircher ('10 a) ('10 b) fed thyroid to young rats and found a retardation in growth and body weight, but an acceleration in the process of ossification.

Utterström ('10) reported an enlargement of the thymus in thyroid-fed rabbits.

Hoskins ('10 a) fed daily, for 15 days varying amounts (5-15 $\mathrm{mg}$.) of thyroid to 18 young guinea pigs. Their suprarenal glands 
were 25 per cent heavier than those of 18 controls. The same author ('10 b) fed thyroid to pregnant guinea pigs. Many abortions and several still-born occurred. The newborn (apparently normal) young of the treated mothers weighed on the average 12 grams less than the controls. The hypophysis showed an average decrease in weight of 10 per cent, the suprarenals 26 per cent and 2 per cent for the females and males respectively; the ovaries 26 per cent; and the thyroid gland 18 per cent. The thymus was increased 58 per cent.

Carlson, Rooks and McKie ('12) and Ferrant ('13) fed thyroid to birds and mammals, including man. They concluded that large doses of thyroid are toxic. In the thyroid fed rabbits of Ferrant the heart, liver and pancreas showed degenerative changes.

Schäfer ('12) fed thyroid to young white rats, noting an increased food consumption, increased metabolism and acceleration of growth.

Gudernatsch ('12, '14) found that thyroid administered to a large number of tadpoles retarded growth (i.e., a toxic effect) but hastened metamorphosis of the limbs and tail. It is probable that this acceleration is due to an increase in the rate of the circulation and general metabolism. Lenhart ('15) reaches the same conclusion. The present writer, in a similar (unpublished) experiment (with larval frogs and Ambystomae) fed large doses and noted only the toxic effect. Coutronei ('14), West ('14), Morse ('15) Abderhalden ('15) and Romeis ('15) have recently confirmed in general the results of Gudernatsch.

Hewitt ('14) fed thyroid gland to white rats, noting a loss in weight.

Livingston ('14) found that feeding thyroid inhibits the hypertrophy of the hypophysis which follows thyroidectomy in male
rabbits.

Gudernatsch ('15) fed thyroid to albino rats. This treatment retarded growth and interfered with pregnancy. The effect produced is probably due merely to the toxicity of thyroid, as Stockard ('13) obtained quite similar results in animals treated with alcohol. 


\section{Thymus feeding}

For complete literature see Vincent ('12), Biedl ('13), Basch ('13) and Paton ('13).

Gudernatsch ('12) ('14) found that a thymus diet stimulated body growth in tadpoles, but retarded metamorphosis of the limbs and tail. Similar results in some cases were obtained by Romeis ('15) and Abderhalden ('15).

Gebele ('11) and Miss Hewer ('14) reported negative results with thymus feeding. In the latter's work, thymus, when fed ( 1 to $4 \mathrm{~g}$. daily) to males, retarded the development of the testes in young rats and caused degeneration of the testes in adults.

Salkind ('15) reported stimulation of growth from feeding large amounts of thymus.

\section{Hypophysis experiments}

Cushing ('12) concludes that total loss of the anterior lobe of the hypophysis is followed by death and that partial loss is followed by obesity, sexual infantilism, and retardation of skeletal growth.

Frequent injections of hypophysis extract interfere with growth, (Cerletti '09, Fodera and Pittau '09). A loss in weight with no skeletal changes is reported by Franchini ('10) and by Crowe, Cushing and Homans ('10). A gain in weight after continued injections of hypophysis extract is reported by Delille ('09), and cardiac hypertrophy by Etienne and Parisot ('08); but Caselli ('00) obtained negative results.

Retardation in growth (especially skeletal) as a result of hypophysis feeding was reported by Thompson and Johnston ('05), Etienne and Parisot ('08), Sandri ('07), ('09) (posterior lobe), and Cushing and Goetsch (cited by Cushing ('12), Wulzen ('14) and by Pearl ('16) (anterior lobe) Abderhalden ('15), and Robertson ('16).

Negative results from feeding hypophysis are reported by Caselli ('00), Sandri ('09) (anterior lobe), Hoskins ('11), Aldrich ('12a) ('12b), Schäfer ('12), Lewis and Miller ('13), and Gudernatsch ('14). 
Schäfer ('09) had thought that feeding small amounts of anterior lobe of the hypophysis favors growth. Goetsch ('16) from very few data reports that excessive dosage retards growth in young rats, whereas smaller dosage accelerates growth in body weight and especially the development of the sexual system; that this acceleration is due to the anterior lobe; and that feeding posterior lobe does not accelerate growth, and even retards sexual development. Robertson ('16a) reports that hypophysis extract accelerates growth after inanition.

So far as the literature shows, in none of the above experiments with hypophysis substance was a complete autopsy performed or complete histological examination made. Hallion and Alquier ('08) report hypertrophy of the suprarenals in rabbits, and no changes in the gonads. Wulzen ('14) noted in chickens fed fresh hypophysis that the long bones were shorter than in her control animals, and that the involution of the thymus was hastened by the treatment.

\section{Pineal experiments}

In experiments on growth, Dana and Berkeley ('13) reported that after injecting and feeding a few young animals with pineal substance, they noted growth acceleration. These results may be due to the pineal medication or merely to normal variation. Berkeley ('14) reported mental and physical improvement in backward children to whom pineal substance was administered.

Priore ('15) reports that young rabbits into which pineal extract was injected frequently, grew slightly more than the controls, but his results are probably within normal variability. In an older group the controls outgrew the experimental group. In none could any skeletal alterations be seen.

MeCord ('14) fed pineal substance to a few chicks, young guinea pigs and pups. He reported an acceleration in their rate of growth, increased mentality in the dogs, and sexual precocity in some of the guinea pigs.

The same writer ('15) later reported that the growth of young guinea pigs which received daily $10 \mathrm{mgms}$. of pineal substanoe from adult cattle was delayed. Adult guinea pigs were not affected by calf pineal substance (dried), but the growth rate 
of young guinea pigs was accelerated by injections of extract of calf pineals. Pineal substance hastened sexual development in guinea pigs. Males were more susceptible than females to pineal treatment. The treated animals did not grow larger than normal adults and their growth was apparently proportional in all parts of the body. The 'sexual precocity' noted by McCord perhaps can be explained by the fact that in growing animals the sexual development normally tends to keep pace with somatic growth. In stunted animals sexual maturity is retarded as seen in inanition experiments (Jackson '15); conversely it is to be expected that a hastened somatic growth is accompanied by a corresponding development of the reproductive organs. This condition can hardly be called sexual precocity, especially if the sex organs are not relatively overdeveloped.

Dandy ('15) was able to remove the pineal body from young dogs with no apparent after-effects.

Many experimental data that have been published are worth very little to us because of incomplete records and also because animals of one strain kept under certain conditions have been used as control animals and checked against experimental animals of a possibly different strain kept perhaps under different conditions. It is also true that in many experiments, although all the animals are of the same strain and are kept under similar conditions, only a small number are used and these represent different litters. Since it has been shown by Jackson ('13) and King ('15) that in albino rats variability in body weight within a litter is only about half as great as general racial variability, the advantage of taking controls and experimental animals from the same litter is obvious. The apparent 'results' obtained in many experiments may very well be due merely to the abovementioned factors and not to the experiment itself.

\section{MATERIAL AND METHODS}

The albino rat (Mus norvegicus albinus) was selected for the experiment because it is a convenient form for use and more is known about the growth of this animal than of any other, owing to the work of Donaldson, Hatai, Jackson, Slonaker, Lowrey, 
King, and others. Owing perhaps to their diet and very favorable environment, most of the animals (especially the younger male groups) are somewhat larger than the average ordinary albino rats at corresponding ages. Twenty-nine litters were used but where litters contained less than four rats of a sex these individuals were usually rejected. A few rats were killed by the mother before weaning time. In all, 59 females and 73 males were fed and of these all of the females and 59 of the males were carefully autopsied at the termination of the experiment. While the number of observations is not large from the statistical point of view, and more would be necessary for final conclusions, it is believed that the present data are sufficient to establish certain points with a considerable degree of probability, and to furnish valuable evidence upon other points requiring further data. Most of the older animals which were born during the summer and early fall were smaller at the beginning of the experiment than were those born in the winter and spring. This is in accordance with previous observations. These initial differences generally persisted throughout the period of experiment (as likewise found by King ('15). Of the older litters, two of which were of purely local stock were quite large rats, whereas three litters which were of pure 'Wistar' stock were considerably smaller. Other litters used were of a mixture of these two strains.

The rats with few exceptions were weaned at 3 weeks of age, and kept in a well ventilated room in fairly large wire net cages, with wire net bottoms which allowed waste matter to drop through. The males and females were of course separated. All were fed (ad libitum) upon whole wheat (Graham) bread soaked in whole milk, a diet which seems to provide abundant nourishment, as shown by the rapid growth of the animals. During the first part of the investigation the rats were fed once a day and their water jars washed once a week. Later all of the animals were fed 3 times a day, the water jars washed daily and at all times the cages were kept clean. Each animal was given a mark of identification with picric acid and a separate growth record kept for it. In general, each rat was weighed at wean- 
ing time, and each day (before feeding) for about a week, but thereafter the interval between weighings was gradually increased.

The autopsy technique employed by Jackson ('13), with a few modifications, was used. The various organs were placed in a moist chamber when taken from the animal and weighed when all had been removed. The thyroid and thymus were freed from their capsules. In the younger groups of animals the mesentery and pancreas were removed from the stomach and intestines. These cases are marked $(c)$ in the tables.

All the organs were weighed in closed containers to. $0.1 \mathrm{mgm}$. The skeleton was prepared by heating the body (eviscerated and skinned) at 90 degrees centigrade for 2 or 3 hours in 2 per cent aqueous 'Gold Dust' (a proprietary soap powder) solution. The skeleton (including cartilages) was cleaned, drained carefully, and weighed, and then dried for 2 weeks (in an oven heated at 88 to 90 degrees centigrade) to constant weight and weighed again. This technique gives fairly constant results.

In the final averages shown in the various tables, extreme data are in a few cases excluded. (These extreme cases were probably due either to experimental error or to abnormal variation.)

The tables show only the averages of individual data. A copy of the original observations have been filed at The Wistar Institute of Anatomy and Biology, Philadelphia, where they may be consulted by those interested.

The material for feeding was obtained every 2 weeks by the author in person, from newly-killed calves 6 to 10 weeks of age, and ground fine in a kitchen meat-grinder. Some of the substance of each kind was spread out thin and dried before an electric fan at room temperature. The material was quite dry within 5 to 10 hours of the death of the calves. It was diluted with known amounts of milk sugar for measuring. A portion of each kind was kept fresh (at from zero to 5 degrees centigrade). No constant difference in the effects produced by the fresh and dry glands was noticeable, so in grouping the 
data the difference in the two conditions of the material administered was disregarded.

The rats used, were grouped to exclude so far as possible the error introduced by the racial variability. One rat of each litter (or one of each sex if both males and females of the litter were used) was kept for control, the remaining being distributed among the groups treated, in such manner that (so far as possible) each group contained individuals from every litter. There are five groups of each sex. To eliminate the 'age' factor, the data for each sex were subdivided into 'older' and 'younger' groups, as.shown in the tables.

In calculating the results, two methods were used. In one the average of the percentage of the net body weight of each organ of each group of experimental animals was compared directly with the average value of that organ in the control group while in the second method a comparison was made with the Wistar reference tables as suggested by Donaldson ('15). In the latter comparison the gross body weight was used instead of the length because the weight of the organs of the controls corresponded somewhat more closely to Donaldson's Wistar norm for rats of the same gross body weight than to those of the same length. The values obtained, however, would have been practically the same in either case.

The tables published by Donaldson ('15) used here are designated as 'Donaldson's Wistar tables' or the 'Wistar norms.'

For the dosage employed see table 3 .

The experiments began when the rats were weaned, at the age of about 3 weeks, excepting 15 rats which were 8 to 11 weeks old. Of these 15 rats, only 4 were autopsied. Each rat was treated on alternate days throughout the entire period of the experiment. Nine litters were given fresh glandular substance, and all others received dried glands. The material to be fed was mixed with a small amount of bread and milk and the animal kept in an individual cage until all of this had been eaten. 


\section{ORIGINAL OBSERVATIONS}

\section{Body as a whole (weight and length)}

a. Comparison of controls with norms. The growth of the younger groups of rats, especially the males, in this investigation varied considerably from that of the rats described by most of the previous workers for rats collected at random from a colony. It is necessary therefore to make a comparison of the animals with the norms of other investigators before discussing the effects of the ductless gland feeding. In this comparison, only the control rats will be considered directly. With the exception of certain data of the thyroid-fed groups which will be discussed later, however, there is a close agreement among the corresponding data of all the groups so that the data of the control animals represent indirectly most of the data of the entire series.

A great difference between my rats (especially the 'younger' or 'winter-born' males) and those previously described by Donaldson and Jackson is to be noticed in the rate of growth both of body length and of body weight. The albino rats described by Donaldson ('06) and by Jackson ('13 and '15) of different strain and different diet are considerably lighter in weight than are mine at corresponding ages, up to the fourth month. (See table 1 and charts 1 and 2). The selected 'strong and vigorous' litters described by King ('15), however, correspond rather closely with mine in body weight.

The rate of growth varies thus in albino rats from different sources, depending partly upon the 'strain,' but more upon diet and general environment. King's results indicate also that a more rapid growth may be expected from those litters in which at birth the individuals are especially large and strong. The vigorous average growth of my rats appears chiefly in those designated as the 'younger' ('winter-born') litters. The growth of the 'older' ('summer-born') animals throughout is more nearly like that found by Donaldson and Jackson (charts 1 and 2; table 1). As the 'younger' group had been eliminated largely at 110 (and partly at 70 ) days, the final averages are relatively 
TABLE 1

Average gross body-weight of normal albino rats at various ages (in comparison with data from Donaldson, Jackson and King), showing variability probably due to various causes.

\begin{tabular}{|c|c|c|c|c|c|c|c|c|}
\hline \multirow{3}{*}{$\begin{array}{l}\text { AGE DAYS } \\
20-21\end{array}$} & \multirow{2}{*}{\multicolumn{2}{|c|}{$\begin{array}{c}\begin{array}{c}\text { Hoskrns } \\
\text { (coNrrots) }\end{array} \\
\text { grams }\end{array}$}} & \multirow{2}{*}{\multicolumn{2}{|c|}{$\frac{\text { KrNG }(' 15)^{1}}{\text { grams }}$}} & \multirow{2}{*}{\multicolumn{2}{|c|}{$\frac{\text { JACKsON ('13) }}{\text { grams }}$}} & \multicolumn{2}{|c|}{ DONALDSON ('06) } \\
\hline & & & & & & & gram & \\
\hline & $(11 \mathrm{~m})^{2}$ & 32.6 & $(50 \mathrm{~m})$ & 32.0 & $(53 \mathrm{~m})$ & 24.0 & $(19 \mathrm{~m})$ & 21.2 \\
\hline & (10f) & 29.6 & $(50 \mathrm{f})$ & 28.0 & (59f) & 21.5 & $(17 \mathrm{f})$ & 22.6 \\
\hline \multirow[t]{2}{*}{$30-31$} & $(18 \mathrm{~m})$ & 46.4 & $(50 \mathrm{~m})$ & 48.5 & & & $(19 \mathrm{~m})$ & 31.8 \\
\hline & (16f) & 44.4 & $(50 f)$ & 45.7 & & & (17f) & 32.9 \\
\hline \multirow[t]{2}{*}{40} & $(18 \mathrm{~m})$ & 69.5 & & & 8 & & & \\
\hline & (16f) & 70.1 & & & & & & \\
\hline \multirow[t]{2}{*}{$42-43$} & $(18 \mathrm{~m})$ & 80.9 & $(50 \mathrm{~m})$ & 78.0 & (45m) & 63.7 & $(19 \mathrm{~m})$ & 46.3 \\
\hline & (16f) & 76.4 & $(50 f)$ & 70.0 & $(50 f)$ & 64.3 & (11f) & 47.9 \\
\hline \multirow[t]{2}{*}{70} & $(18 \mathrm{~m})$ & 164.2 & $(50 \mathrm{~m})$ & 143.0 & $(23 \mathrm{~m})$ & 130.4 & $(19 \mathrm{~m})$ & 106.6 \\
\hline & (16f) & 127.3 & $(50 f)$ & 123.0 & (25f) & 108.9 & (11f) & 99.8 \\
\hline \multirow[t]{2}{*}{90} & $(15 \mathrm{~m})$ & 184,6 & $(50 \mathrm{~m})$ & 184.8 & & & & \\
\hline & (13f) & 143.3 & $(39 f)$ & 148.0 & & & & \\
\hline \multirow[t]{2}{*}{$110-112$} & $(11 \mathrm{~m})$ & 205.9 & $(50 \mathrm{~m})$ & 214.0 & & & $(19 \mathrm{~m})$ & 183.8 \\
\hline & $(10 f)$ & 151.6 & $(42 f)$ & 166.0 & & & (11f) & 160.2 \\
\hline \multirow[t]{2}{*}{150} & $(5 \mathrm{~m})$ & $221.5^{3}$ & $(50 \mathrm{~m})$ & 243.0 & $(20 \mathrm{~m})$ & 167.5 & $(19 \mathrm{~m})$ & 225.4 \\
\hline & (8f) & 164.6 & (45f) & 185.0 & (21f) & 142.1 & (11f) & 184.6 \\
\hline
\end{tabular}

${ }^{1}$ King's data partly from her table 3 , partly estimatod from her chart 3.

2 The 21 day group includes only the larger 'winter-born' rats.

'The 150 day group includes only the smaller 'summer-born' group.

lower. At 150 days (table 1 ) the averages are slightly less than Donaldson's and King's, but somewhat greater than Jackson's.

As shown in table 1, the females at six weeks (40 days) average heavier than the males in the control group. This agrees with the results of Donaldson ('06) and Jackson ('13), but not with King ('15).

The difference in the rate of growth of the body length and tail length of my rats, as compared with the data of Jackson ('15) and of Donaldson's Wistar tables is shown in table 2. It may be seen that my rats averaging 13 weeks old are longer than Jackson's rats at 5 to 13 months. Had the table included my entire autopsied series of 59 males and 59 females the difference would have been slightly greater, as seen in tables 6 and 7 . The ratio between the tail length and the body length is dif- 


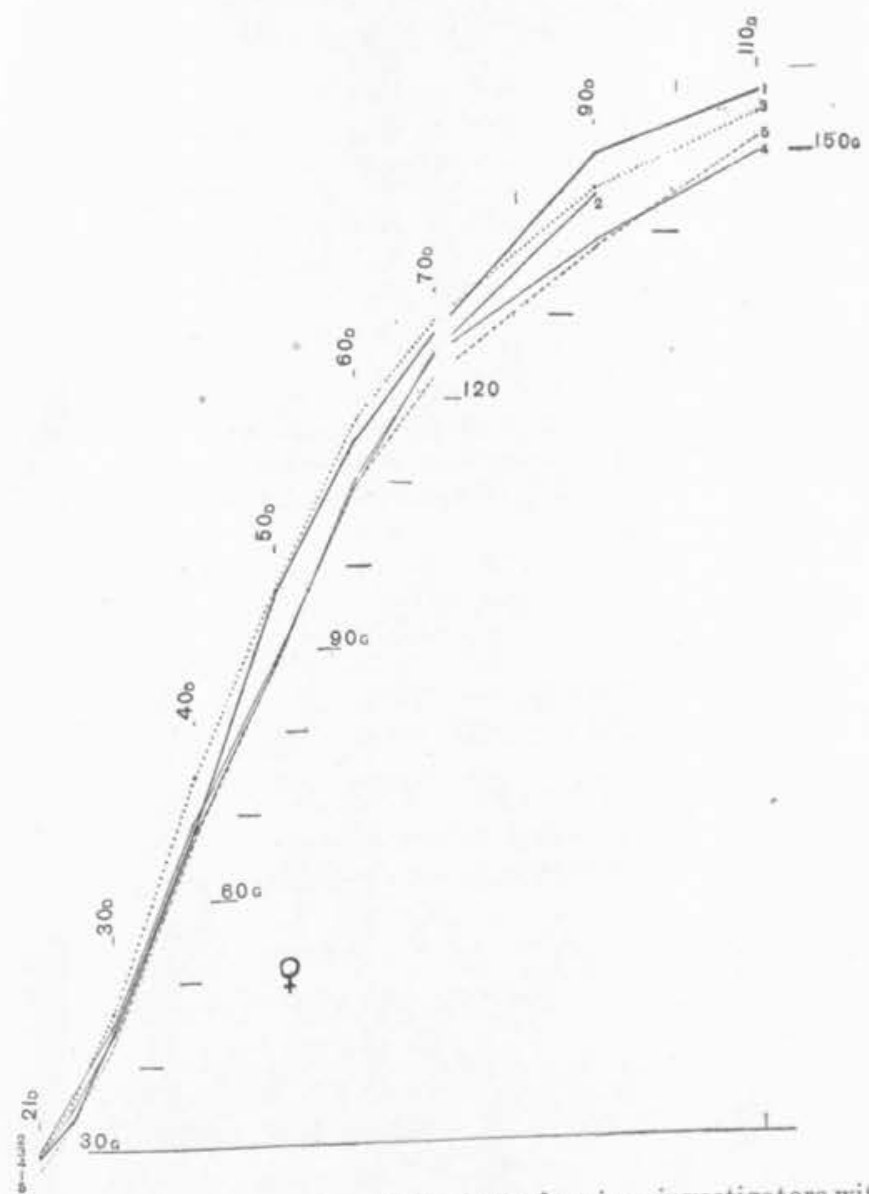

Chart 1 A graphic comparison of the data of various investigators with those Hoskins for the growth of normal female albino rats. The weight in grams is plotted against the age in days. D., Donaldson '06, J., Jackson '13; K., King '15; (low dosage) group of control female rats and $H^{1}$, Hoskins' H., Hoskins' older (low dosage) group of fudden flattening of younger (high dosage) group of contrc the graphs $H^{1}$ and $H$ after 70 and 90 days respective The curves $H^{1}$ and $H$ are not that at these points autopsy of rats was begun. The points, because in most cases closely comparable with the others after these the largest rats were killed first. 


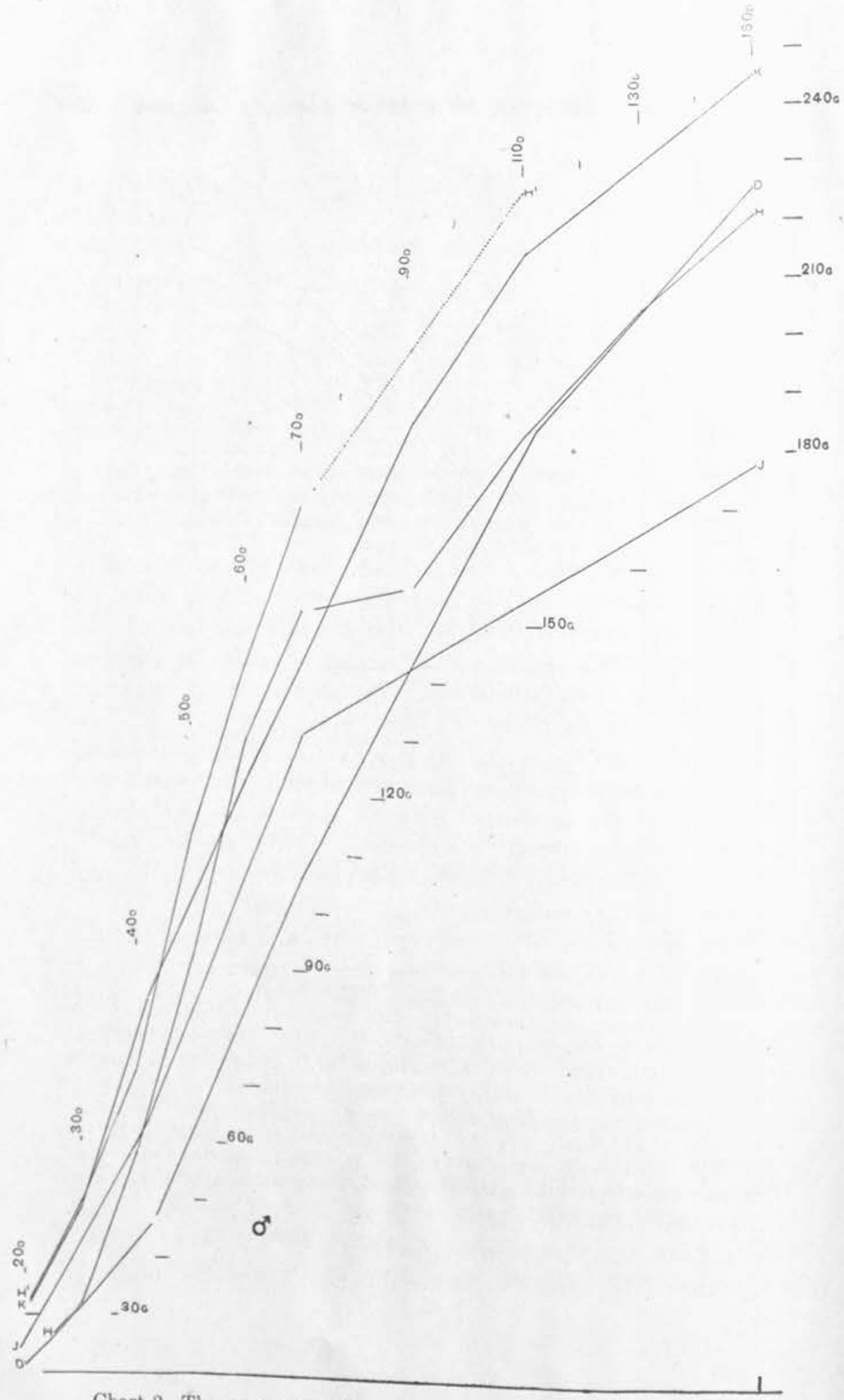

Chart 2 The same as in Chart 1, except that it is for normal males. For further explanation, see that given for chart 1 . 
TABLE 2

Comparison of data for younger and older groups of control (muscle-fed) albino rats with Jackson's data and Donaldson's tables, showing growth of body length and tail length.

\begin{tabular}{|c|c|c|c|c|c|c|c|c|}
\hline \multirow[b]{3}{*}{ Number and sex.... } & \multicolumn{4}{|c|}{ HOSKINS } & \multirow{2}{*}{\multicolumn{2}{|c|}{$\begin{array}{l}\text { 1Acksos ('15) } \\
\text { 5-13 Mo. }\end{array}$}} & \multirow{2}{*}{\multicolumn{2}{|c|}{$\begin{array}{l}\text { DONALDSON'S TABLES } \\
\text { (AT CORREGPONDINO } \\
\text { BODY LENGTHS) }\end{array}$}} \\
\hline & \multicolumn{2}{|c|}{$\begin{array}{l}\text { Younger group } \\
\text { (av. } 13 \text { weeks) }\end{array}$} & \multicolumn{2}{|c|}{$\begin{array}{l}\text { Older group } \\
\text { (av. } 28 \text { weeks) }\end{array}$} & & & & \\
\hline & $8 \mathrm{~F}^{*}$ & $10 \mathrm{M}^{*}$ & $8 \mathrm{~F}$. & $6 \mathrm{M}$. & $34 \mathrm{~F}$. & I6M. & F. & M. \\
\hline Body length, cm..... & 18.7 & 20.3 & 19.4 & 21.2 & 18.3 & 19.0 & $18.7-19.4$ & $20.3-21.2$ \\
\hline Tail length, em..... & 16.0 & 16.5 & 16.5 & 16.6 & 16.8 & 16.2 & $16,4-17,0$ & $17.2-18.0$ \\
\hline Tail Body-Ratio.... & 0.86 & 0.81 & 0.85 & 0.78 & 0.90 & 0.86 & 0.88 & 0.85 \\
\hline
\end{tabular}

* If all the thirteen weeks old rats on experiment are included, the number of females and males changes to 28 and 29 respectively, and the lengths of the body and of the tail are but very slightly changed. (See tables 7 and 8.)

ferent in the different series. In all of my groups of rats the tails are relatively shorter than those of Jackson's rats, and than those at corresponding body lengths in Donaldson's tables. If, instead of the age, the body weight is taken for the basis of comparison, a similar difference in the ratio of the tail length to the body length of the two series is evident.

The growth of the albino rat in weight and length under different circumstances thus varies considerably. A norm must therefore be established not only for each strain but also for each litter under a given set of environmental conditions. If, however, similar litters from the same strain are kept under similar conditions variability will be at a minimum.

For a comparison of the various organs and parts of the rats with those described by previous writers, data are shown in tables 8 and 9 for relative (percentage) weights, and in tables 4, 5, 6 and 7 for absolute weights. Data from Donaldson's Wistar tables for rats of corresponding body weights and lengths are.included in tables 4 and 5 . The body weight in general is slightly greater in the Wistar norms than in my rats of corresponding body length, excepting the younger males. As to the individual organs, it is evident that in some cases the, weights in my series are nearer to those of Donaldson's tables at corresponding body lengths, while in others they are nearer those of corresponding body weight. Some differences are due probably 
to age. On the whole, the correspondence with the Wistar tables is as close as could be expected. The individual organs will be considered later.

b. Effects of thyroid, thymus, hypophysis and pineal feeding. The weight and length of the growing albino rats fed various ductless glands are shown in tables 6 and 7, and (for the 'higher dosage' groups) in charts 3 and 4 . For the sake of elimination of any variation that might be due to the age of the rats, each sex group was subdivided into 2 smaller ('old' and 'young') groups, depending upon the age of the individuals. Some of the younger animals received fresh and some dried glands (see 'Material and Methods'), but no difference was noticed in the effects produced by the two forms.

The effect of a ductless gland diet upon the growth of the females is seen in table 6 and chart 3 . The various experimerital groups may be compared with each other or with the controls, and it is found that the difference in weight at every age is remarkably slight. At the beginning of the experiment when the rats were 3 weeks old the different groups averaged nearly the same in weight, excepting the male thyroid group and the pineal groups. Into these groups were purposely placed slightly more than their share of smaller animals because it has recently been claimed that thyroid and pineal substances accelerate growth in various species (Schäfer '12) (Dana and Berkeley '13, MeCord '14). At 70 days of age, when the period of most rapid growth had ended, it is seen that among the younger ('higher dosage') animals there had been a remarkably small difference in the growth rate of the various groups. The same is true of the older rats, if the thyroid group (which contains 2 rats that were not healthy) is left out of consideration. At 90 days of age the weights of the different groups still remain fairly close together. After 70 days the groups are no longer directly comparable because many of the rats had been killed. Upon the comparison of individuals within each litter, no constant difference appears, although considerable variation is shown. The only probable conclusion to be drawn is that the glandular substances (in 


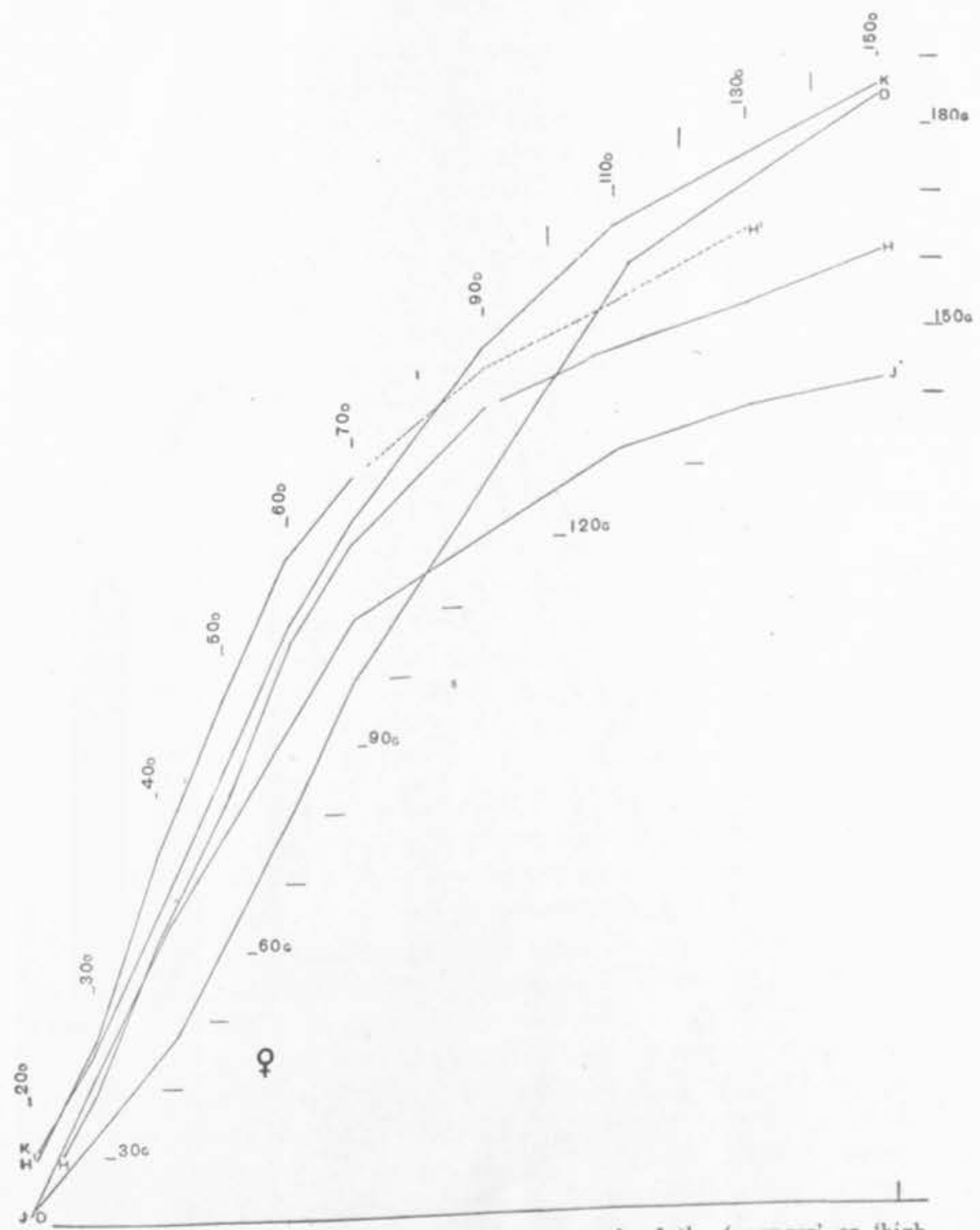

Chart 3 Graphic representation of the growth of the 'younger' or 'high dosage' female albino rats to which ductless glands were fed. The weight in is plotted against the age in days. 1. Thyroid-fed; 2 , Thymus-fed; 3 , (controls; see also chart 1); 4 . Hypophysis-fed; 5 , Pineal-fed. Note Muscle-fed (controls; see also eharee in weight. At 70 days, autopsy of the larghow closely the various groups agree in weight.

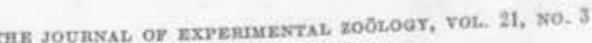




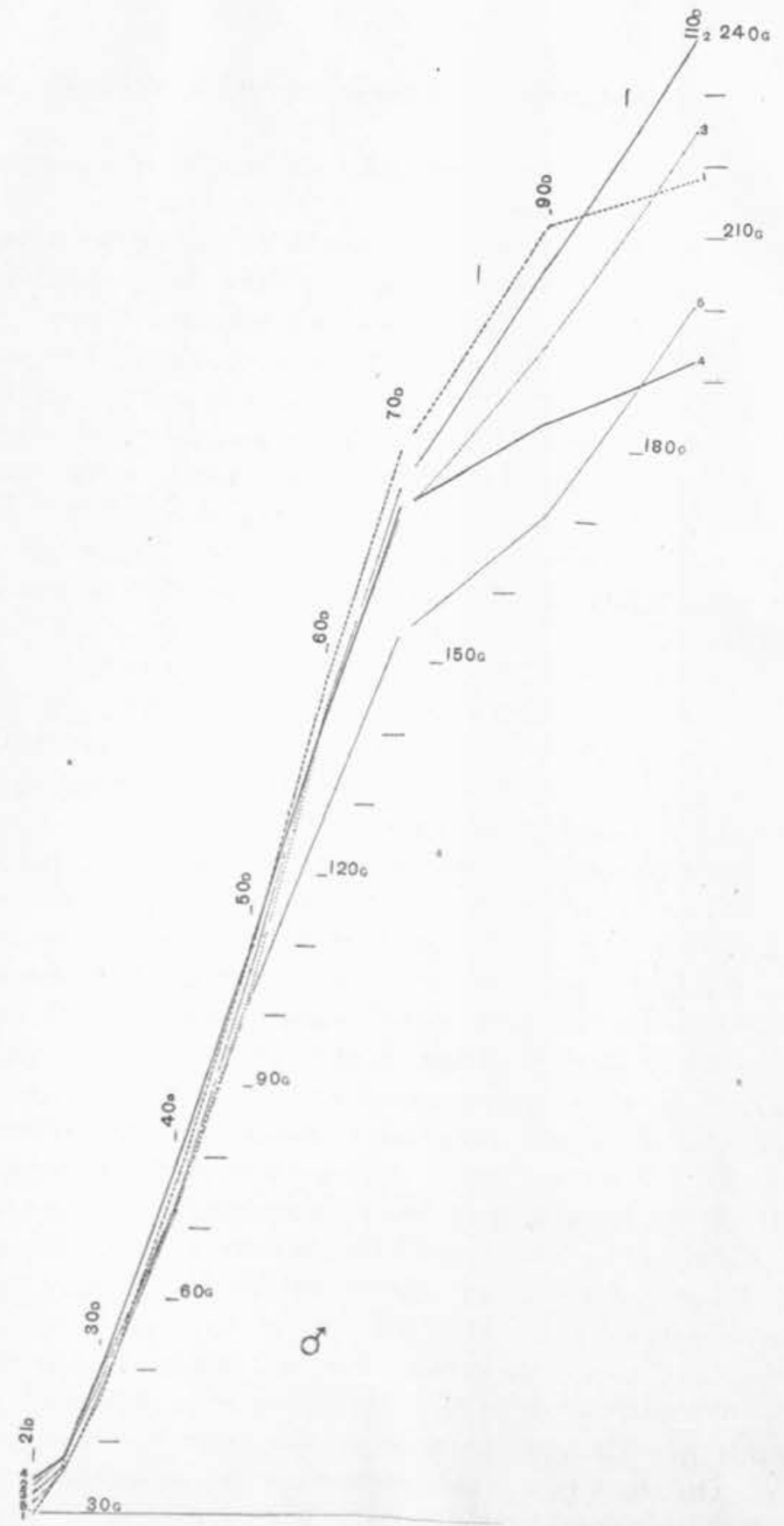

Chart 4 The same as chart 3 , except that it is for males. The flattening of the graphs between 21 and 25 days (as compared with those of the females, chart 3 ) possibly indicates that males are more susceptible to environmental changes than are females. The rats were weaned at 21 days. 
the amounts fed) had no effect upon the weight of the female albino rats in this experiment.

A graphic representation of the growth of the 'higher dosage' group of females is shown in chart 3 . The body weights in all cases remain close to those of the controls (muscle-fed). In the 'higher dosage' groups, the body weights (chart 1) are seen to be much higher than the normals of Jackson and also of Donaldson (excepting near the end of the experiment). In the 'lower dosage' groups the body weights average lower, more nearly comparable to the normals of Jackson and Donaldson. This difference in body. weight between the 'higher dosage' groups and the 'lower dosage' groups is not due to the different amounts of ductless glands fed, however, as a similar difference is shown by the controls in each group. A careful study of the growth of individuals within each litter shows that in nearly every instance those rats which at three weeks were larger (or smaller) than the controls retained the same relative position as regards body weight throughout the experiment.

The male albino rats to which ductless glands were fed also seemed not to be affected in body weight by the treatment. A careful study of table 7 and chart 4 shows nearly the same facts for the male rats as have just been stated for the females. The weights of the different 'higher dosage' groups are unusually close together at 70 days of age, except in the case of the pinealfed. The 'higher dosage' pineal-fed animals at this age are 16.5 grams lighter in weight than the controls; but this difference is not great, and as this group averaged less in weight than the controls at the beginning of the experiment, the difference in weight between the two is probably due to normal variation. In the 'lower dosage' group, the pineal-fed are slightly above the controls in weight. After 70 days of age many rats were autopsied and hence the groups are no longer directly comparable, but individuals of the same litter were compared with each other and showed the same results as in the case of the females. On the whole, there appears to be no evidence indicating that the ductless gland feeding has naterially affected the body weight in any case. The differences are inconstant, and well within the limits of the variability to be expected. 
It may be noted (see table 3 ) that thyroid was fed in varying amounts from the negligible quantity of $10 \mathrm{mgms}$. of dried gland on alternate days to a nearly maximum non-toxic dose of $200 \mathrm{mgms}$. of dried substance (or an equivalent armount of fresh gland) on alternate days. In all cases no appreciable

TABLE 3

Amount and range of dosage employed for each rat in feeding the various groups. The growth in body weight for the 'high dosage' groups is represented in charts 3 and 4.

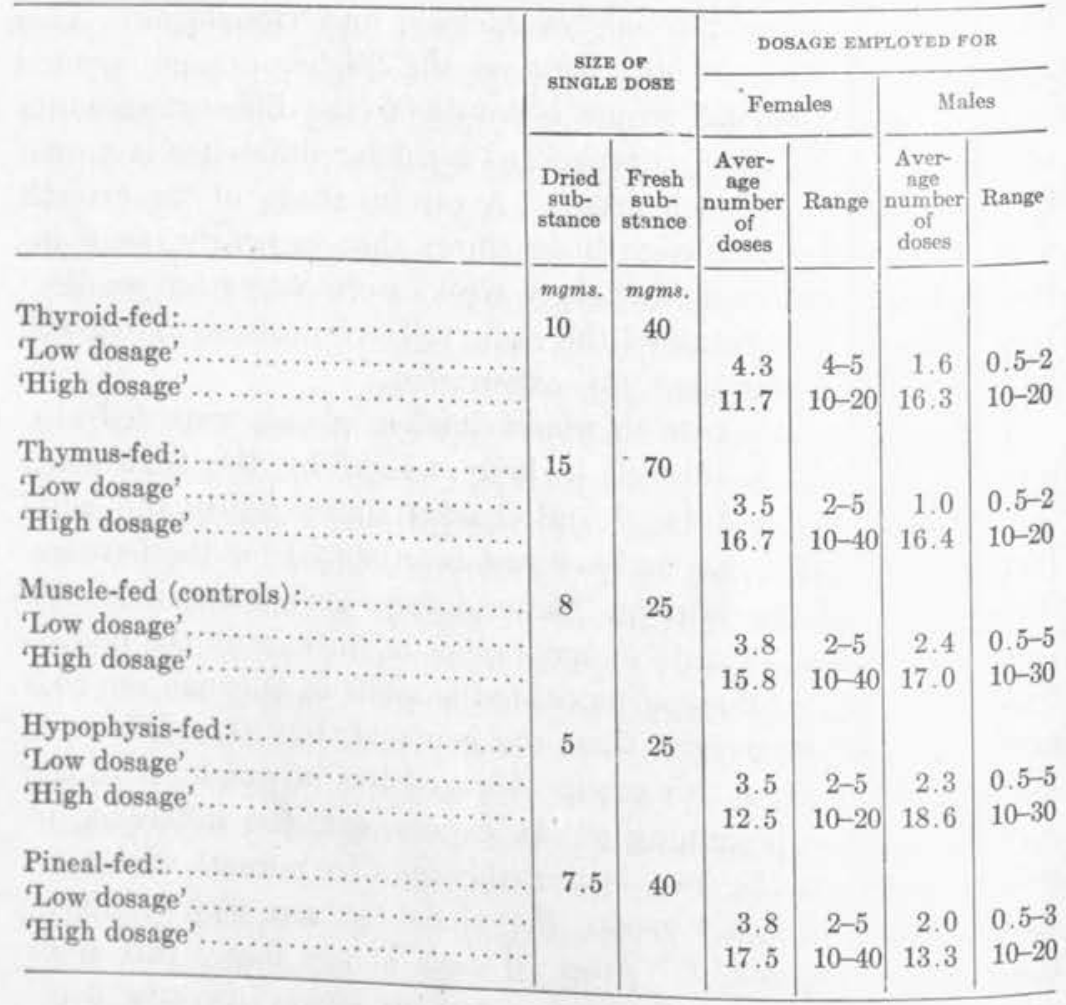

effect upon the growth of the body as a whole was evident. Thymus was fed in variable amounts up to $300 \mathrm{mgms}$. of dried substance, but two individuals receiving twice this amount showed no effects different from the others. Hypophysis was administered in fairly small doses (5 to $100 \mathrm{mgm}$. of dried sub- 
stance). Pineal substance was given in amounts larger than those fed to guinea pigs (in most eases) by MeCord ('14), but in one of McCord's experiments where doses of $100 \mathrm{mgms}$. of dried substance was used daily, the experimental animals in a given time grew in weight 40 per cent more than the controls. As stated above, there seemed to be no difference in the result with albino rats in the present experiment, whether small amounts of $20 \mathrm{mgms}$. or larger amounts up to $150 \mathrm{mgms}$. of dried pineal substance was fed on alternate days. With the larger doses there was no evidence indicating that toxic effects of gastrointestinal disturbances were produced by the medication.

As shown in tables 2, 6 and 7 , the various rats of the same age and sex are also of nearly the same body-length regardless of treatment. The agreement here is even closer than in regard to comparative weights and emphasizes still more strongly the fact that the experimental rats as compared with the controls suffered no marked gross body changes on account of the administration of ductless glands.

The growth records of the individual rats illustrate, as has been pointed out above, that very serious errors might easily creep into the conclusions from an investigation of this kind, which includes animals from several different litters. A preliminary comparison of the individuals in each litter showed negative results, so all were finally grouped as shown in the various tables. There is always, of course, some danger in drawing conclusions from averages, but this danger is slight if the individual data are also carefully studied, and the grouping judiciously made.

Care must be taken in work of this nature to select experimental and control animals from the same litter and as nearly alike as possible. In many investigations on growth this has not been done. Experimental groups of animals of one sex have even been compared with groups of another sex; or, more commonly, an experimental group has contained both sexes in a ratio different from that in the control group.

Finally, the depressing effects upon growth and body weight obtained by some investigators by the administration of ductless glands especially the thyroid (Magnus-Levy, Bircher, Carlson, Far- 
rant, Gudernatsch, Cotroni, Hewitt, Romeis, Lenhari), is in many cases possibly a general toxic effect, which is prodnced whenever the dosage is too high. Even a high protein diet, e.g., an excessive meat diet, may likewise be detrimental to growth, as has been shown for the albino rat by Chalmers Watson ('06).

\section{Head}

Data for percentage weights of head (and other organs and parts) are found for females in table 8 , and for males in table 9. Absolute weights are given in tables 6 and 7 .

a. Controls. The head forms an average of 9.5 per cent of the body weight in the females and 8.3 per, cent in the males among my younger control rats. In the older groups, the head averages 10.3 per cent in the females, and 8.4 per cent in the males. These results are in general somewhat lower than those obtained by Jackson ('13, '15).

b. Thyroid group. The head averages very slightly heavier in both females and males to which thyroid was fed. The difference is probably insignificant.

c. Thymus, hypophysis and pineal groups. The head in these groups shows no constant variation from the controls in either direction. The few small differenees are probably not significant.

\section{Eviscerated Body (Tables 6 to 9)}

a. Controls. The eviscerated body forms an average of 80 to 84 per cent of the net body weight in both males and females. This part of the body contains the muscles, skin, skeleton, bodyfat, great vessels, lymph nodes, and spinal cord.

b. Thyroid group. The eviscerated body in all rats of both sexes (excepting 3 old males, in which the dosage was slight) is about 4 per cent less in relative (percentage) weight than that of the controls. This loss is due probably to loss of fat, which is a well-known effect of thyroid-feeding, especially with high dosage. A comparison of the body weights and body lengths in the control (muscle-fed) and thyroid groups shows a 
slight relative decrease in weight in the thyroid males of higher dosage, but not in the females.

c. Thymus, hypophysis and pineal groups. In all these groups, the weight of the eviscerated body is very close to that of the controls (muscle-fed). The variations are slight and probably insignificant.

\section{Integument (tables 6 to 9 )}

a. Controls. The average relative (percentage) weight of the integument is relatively fairly close in the various groups of both sexes. In general, the percentages range between 21 and 24 per cent of the net body weight, the value for the male rats being slightly greater than for the females, due possibly to the presence of a greater amount of fat in the latter. This is somewhat higher than that observed by Jackson and Lowrey ('12), by more than 4 per cent of the entire net body weight, and is 2 per cent of the entire body weight higher than that observed by Jackson ('15). These differences are probably due largely to the varying amount of fat (or muscle) present in the integument.

b. Thyroid group. In the thyroid rats of each sex the integument appears usually very slightly lighter in weight than in the controls, owing probably to loss of fat. Jackson ('15) has shown that during inanition the skin loses greatly in weight (probably due chiefly to loss of fat) but that the relative (percentage) weight remains unchanged in adults.

c. Thymus, hypophysis and pineal groups. In these groups, the differences in weight of the integument, as compared within each group and with the controls (muscle-fed), are well within the limits of normal variation.

\section{Cartilaginous skeleton (tables 6 to 9 )}

a. Controls. The relative weight of the 'wet' eartilaginous skeleton averages about 7.6 per cent of the body weight in the older females, and about 6.6 per cent in the older males. The skeleton in the younger females averages about 6.8 per cent of 
the net body weight and in the younger males about 6.1 per cent. These correspond fairly well with the estimate of Jackson ('15) which was 7 per cent of the adult net body weight, and with Conrow's observations (cited by Donaldson '15, table 53). The difference between the sexes is accounted for by the heavier body weight (with correspondingly lighter skeleton) in the male groups, rather than by any true sexual difference.

The older groups of each sex on the average appear to have a relatively heavier skeleton than the younger. This is contrary to the general tendency of the skeleton during growth to lag behind in relative weight. In these groups, however, the differences in body weight are much less than usual for the corresponding age differences, and the increased weight in the older skeletons is possibly due to more advanced stages of ossification and calcification. Thus in two animals of the same body weight, the older apparently has a heavier skeleton. This tendency is not evident in Conrow's data (cited by Donaldson '15), however.

In this connection may be cited the observations of Jackson ('15) who found that in young rats held at constant body weight by underfeeding the skeleton continues its development (differentiation and increase in wet and dry weights). It is therefore probable that the relative weight of the skeleton depends somewhat upon the age factor, as skeletal growth is to some extent independent of the general growth of the body.

The dry cartilaginous skeleton is likewise relatively slightly heavier in the female ( 3.7 to 4.6 per cent) than in the male ( 3.2 to 3.8 per cent), and the older rats of both sexes have relatively heavier dry skeletons than the younger. The explanation for this is doubtless the same as that above given for similar relations in the weights of the wet skeleton in different groups. There is considerable variation shown by individuals, so that the average values for both wet and dry skeleton can be considered as only approximate. Differences in the technique may also modify the skeletal weight considerably. For example, Conrow's data for the dry skeleton (cited in Donaldson's table 53) are too high, because her method of drying at room tempera- 
ture is inadequate to remove all the moisture. More data are needed to establish a satisfactory norm.

b. Thyroid groups. The skeleton appears slightly heavier for the thyroid treatment in the average of the younger groups. A comparison of the individual data shows that both wet and dry skeletons average somewhat heavier in most of the rats receiving higher dosage of thyroid than in those of low dosage and controls. This suggests that the thyroid treatment may perhaps tend to stimulate skeletal development, as claimed by Bircher ('10b). However, the possibility of errors from accidental variations must be kept in mind, as the differences found are not very great, and were not constant in every litter.

c. Thymus, hypophysis, and pineal groups. The various groups fed thymus, hypophysis and pineal glands show no important or constant variation from the controls in regard to the skeleton. If any effect was produced, it is so slight as to be masked by normal variation.

\section{Brain (tables 4 to 10 )}

a. Controls. As shown by tables 4 and 5 , the absolute weight of the brain does not vary greatly from that shown by Donaldson's tables for rats of similar sex and body weight or body length.

In percentage weights, as might be expected, the males have relatively lighter brains than the females, and the older' brains average lighter than the younger, on account of the fact that the brain lags behind in the growth of the body.

b. Thyroid groups. On comparing directly the average relative (percentage) weights (tables 8 and 9 ) of the controls (muscle-fed) and thyroid-fed animals, the brain in the latter appears slightly heavier in all except the younger group of males; but on comparing the absolute weights with the Wistar norms for animals of corresponding body weight, it is found that the difference in the various litters is not constant and the brain of the thyroid-fed rats averages even smaller than the normal (table 10). 
c. Thymus, hypophysis, and pineal groups. There is no constant variation of the brain in these groups. There appears to be a slight tendency to increase in the brains of the hypophysis-fed group (less marked than in the case of the thyroid), but the difference is not constant.

\section{Eyeballs (tables 4 to 10)}

a. Controls. The absolute weight of the eyeballs in my animals corresponds fairly closely to that of Donaldson's norms (excepting the younger males), as shown in tables 4 and 5 . In comparing the relative weights of groups of each sex (tables 8 and 9) the eyeballs appear relatively heavier in the older groups, although in these, with heavier body weight, the eyeballs would be expected to be relatively lighter. As suggested by Jackson

\section{TABLE 4}

Comparison of principal data for control female albino rats with the Wistar tables of Donaldson ('15). Weight is the average expressed in grams. Comparison is made with Wistar norms both of the same body length and of the same gross body weight.

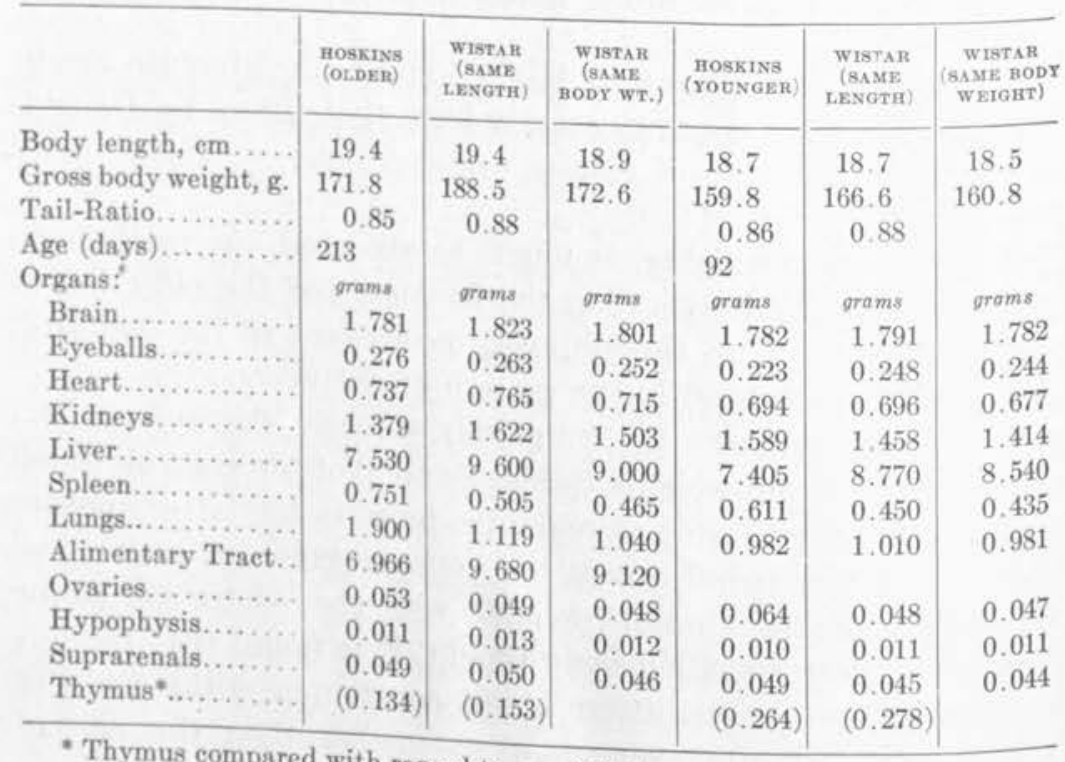

- Thymus compared with regard to age (213 days average for the older group, and 92 days for the younger group) instead of regard to body length or weight. 
TABLE 5

Comparison of principal data for control male albino rats with the Wistar Tables of Donaldson ('15). Weight is the average expressed in grams. Comparison is made with the Wistar norms of the same body length and of the same gross body weight.

\begin{tabular}{|c|c|c|c|c|c|c|}
\hline & $\begin{array}{l}\text { HOsKrNs } \\
\text { (OLDER) }\end{array}$ & $\begin{array}{l}\text { WIBTAR } \\
\text { (SAME } \\
\text { LEN } A T H \text { ) }\end{array}$ & $\begin{array}{c}\text { WISTAR } \\
\text { (SAME BODY } \\
\text { WELGIT) }\end{array}$ & 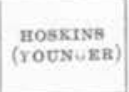 & $\begin{array}{l}\text { WI8TAR } \\
\text { (8AME } \\
\text { LENGTH) }\end{array}$ & $\begin{array}{c}\text { WLTAR } \\
\text { (BAME HODY } \\
\text { WETGHT) }\end{array}$ \\
\hline Body length, cm..... & 21.2 & 21.2 & 21.1 & 20.3 & 20.3 & 20.6 \\
\hline Gross body weight, g. & 232.5 & 238.1 & 234.1 & 214.9 & 204.3 & 215.0 \\
\hline Tail-Ratio........... & 0.783 & 0,85 & 0.85 & 0.813 & 0.85 & 0.85 \\
\hline Age (days)... & 193 & & & 90 & & \\
\hline Organs: & grams & $\begin{array}{l}\text { grams } \\
1.911\end{array}$ & $\begin{array}{l}\text { gramn } \\
1.907\end{array}$ & $\begin{array}{l}\text { grama } \\
1.909\end{array}$ & $\begin{array}{l}\text { grams: } \\
1.872\end{array}$ & $\begin{array}{l}\text { orams } \\
1.885\end{array}$ \\
\hline Brain........ & 1.852 & $\begin{array}{l}1.911 \\
0.294\end{array}$ & $\begin{array}{l}1.907 \\
0.291\end{array}$ & $\begin{array}{l}1.909 \\
0.220\end{array}$ & $\begin{array}{l}1.872 \\
0.273\end{array}$ & $\begin{array}{l}1.885 \\
0.280\end{array}$ \\
\hline Eyeballs....... & 0.286 & $\begin{array}{l}0.294 \\
0.918\end{array}$ & $\begin{array}{l}0.291 \\
0.905\end{array}$ & 0.988 & 0.814 & \\
\hline Heart.... & 0.893 & $\begin{array}{l}0.918 \\
1.992\end{array}$ & $\begin{array}{l}0.905 \\
1.962\end{array}$ & 2.050 & 1. 740 & $\begin{array}{l}0.847 \\
1.820\end{array}$ \\
\hline $\begin{array}{l}\text { Kidneys. } \\
\text { Liver. }\end{array}$ & 1.867 & $\begin{array}{r}1.992 \\
11.440\end{array}$ & $\begin{array}{r}1.962 \\
11.290\end{array}$ & 10.915 & 10.200 & $\begin{array}{r}1.820 \\
10.500\end{array}$ \\
\hline Liver... & 10.701 & $\begin{array}{r}11.440 \\
0.630\end{array}$ & $\begin{array}{r}11.290 \\
0.620\end{array}$ & 0.895 & 0.545 & $\begin{array}{r}10.590 \\
0.572\end{array}$ \\
\hline Spleen... & 0.959 & $\begin{array}{l}0.630 \\
1.365\end{array}$ & & 1.199 & $\begin{array}{l}0.540 \\
1.108\end{array}$ & 0.572 \\
\hline Lungs.............. & 1. 813 & $\begin{array}{r}1.365 \\
11.360\end{array}$ & $\begin{array}{r}1.346 \\
11.230\end{array}$ & & 1.198 & 1.251 \\
\hline Alimentary Tract & 9.351 & 11.360 & $\begin{array}{r}11.230 \\
2.375\end{array}$ & 2.248 & & \\
\hline Testes.......... & 2.222 & 2.397 & $\begin{array}{l}2.375 \\
0.008\end{array}$ & 0.008 & $\begin{array}{l}2.203 \\
0.008\end{array}$ & 2.267 \\
\hline Hypophysis. & 0.009 & 0.009 & $\begin{array}{l}0.008 \\
0.038\end{array}$ & 0.031 & 0.008 & 0.008 \\
\hline $\begin{array}{l}\text { Suprarenals. } \\
\text { Thymus*.... }\end{array}$ & 0.031 & 0.038 & & $\begin{array}{c}0.031 \\
(0.298)\end{array}$ & $\begin{array}{c}0.035 \\
(0.283)\end{array}$ & 0.036 \\
\hline Thymus*..... & $\cdot(0.155)$ & $(0.170)$ & & & $(0.283)$ & \\
\hline
\end{tabular}

* Thymus compared with regard to age (193 days average for older group, and 90 days average for younger group) instead of regard to body length or weight.

('13), however, the growth of the eyeballs may tend to be correlated with age, rather than with body weight (as is known to occur in the thymus). These differences may therefore be due to age changes, to normal variability, or perhaps merely to differences in the technique of removal of the eyeballs.

b. Thyroid groups. The eyeballs average heavier in relative weight than those of the controls in both sexes, but the differences obtained are slight and probably of no significance. Comparison according to the method of Donaldson ('15) shows them slightly lighter in weight in the males than those of the corresponding controls, but in the females slightly heavier.

c. Thymus, hypophysis and pineal groups. In most cases, the eyeballs in these groups average relatively slightly heavier than those of the controls. No particular significance other than variability is attached to this fact. 


\section{Thyroid Gland (tables 6 to 9)}

a. Controls. The thyroid of my rats cannot be compared directly with that of other investigators owing to the different technique with which it was removed from the body, as described in 'Material and Methods.' The weight is about onethird less than the Wistar norm, probably on account of removal of the capsule. There is also extreme variation in the weight of this gland even in different members of the same litter. Usually it appears relatively heavier in the older than in the younger rats, and also slightly heavier in females. Jackson '(13) and Hatai ('13) also have found the thyroid gland to be exceedingly variable, so no final conclusions can be drawn as to the normal weight of this gland.

b. Thyroid groups. The thyroid gland (tables 6 to 9 ) shows no constant changes as a result of the thyroid feeding. Any effect if produced is hidden by the great normal variability. In view of the great variability in the weight of this organ, final conclusions in regard to the effect of thyroid feeding upon the weight of the thyroid gland are not justified from the available
observations.

c. Thymus, hypophysis, and pineal groups. In these groups likewise the thyroid appears variable when compared with the controls, and the results are not sufficiently marked or constant to warrant any conclusion regarding the effects upon the weight of the thyroid gland of feeding these substances.

\section{Thymus (tables 4 to 9 )}

a. Controls. The thymus also is not to be compared very closely with that described by previous workers. The usual method of comparison considers the weight of the gland at difcreases in size gradually, the organ in the albino rat inmaximum weight of 0.29 until at about 85 days it reaches its many conditions 0.29 grams (Hatai '14), but as is well known, weight varies considerably the involution of this organ. Its when the animals are apparently normal and kept under nearly 
TABLE 6

Females: Average absolute weight (in grams) of parts in albino rats grouped according to diet and age when autopsied

\begin{tabular}{|c|c|c|c|c|c|c|c|c|c|c|}
\hline & \multicolumn{2}{|c|}{ THYROID-YED } & \multicolumn{2}{|c|}{ THYMUS-FED } & \multicolumn{2}{|c|}{ MUSCLEEFED (CONTROLS) } & \multicolumn{2}{|c|}{ - HYPOPHYYIS-FED } & \multicolumn{2}{|c|}{ PINYAL-PED } \\
\hline & Old & Young & Old & Young & Old & Young & Old & Young & Old & Youns \\
\hline Number of rats......... & 5 & 4 & 5 & 6 & 8 & 8 & 6 & 5 & 7 & 5 \\
\hline Average age (days) $\therefore$. & 207 & 80 & 215 & 88 & 213 & 92 & 196 & 92 & 214 & 95 \\
\hline Gross body weight, g. . & 160.2 & 145.3 & 158.0 & 156.3 & 171.9 & 159.9 & 166.1 & 149.6 & 173.3 & 146.2 \\
\hline Net body weight, g. .... & 169.7 & 140.2 & 151,3 & 149.1 & 165.4 & 152.9 & 151.8 & 142.4 & 164.7 & 138.3 \\
\hline Body length, cm........ & 19.3 & 18.4 & 18.9 & 18.5 & 19.4 & 18.7 & 18.8 & 18.6 & 19.5 & 18.3 \\
\hline Tail length, cm.......... & 15.9 & 16.0 & 16.4 & 15,6 & 16.5 & 16.0 & 15.3 & 16.0 & 15.9 & 15.6 \\
\hline Average number doses... & 8.6 & 12.5 & 11.7 & 16.7 & 11.6 & 16.3 & 12.8 & 12.0 & 11.9 & 20.0 \\
\hline Average weight of: & grams & grams & grams & grams & grams & grams & grams & grams & grams & grams \\
\hline Head............... & 15.6 & 13.4 & 15.8 & 13.9 & 16.3 & 1,41 & 15.6 & 14.4 & 16.3 & 14.0 \\
\hline Eviscerated body.... & 127.6 & 125.7 & 123.5 & 135.8 & 148.5 & 128.7 & 128.4 & 126.4 & 143.9 & 117.9 \\
\hline $\begin{array}{l}\text { Integument............ } \\
\text { Wet cartilaginous }\end{array}$ & 31.5 & 32.5 & 32.4 & 33.9 & 36,3 & 31.7 & 31.2 & 32.0 & 35.3 & 29.2 \\
\hline $\begin{array}{l}\text { Wet cartilaginous } \\
\text { skeleton.............. } \\
\text { Dry cartilaginous }\end{array}$ & 11.24 & 9.95 & 10.88 & 7.94 & 11.18 & 10.39 & 11.94 & 10.22 & 12.05 & 10.40 \\
\hline skeleton............. & 6.69 & 5.49 & 6.63 & 5.23 & 7.47 & 5.51 & 7.02 & 5.64 & 7.332 & 5.623 \\
\hline Brain ................. & 1. 714 & 1.723 & 1. 683 & 1.742 & 1.781 & 1.782 & 1.714 & 1.806 & 1.858 & 1.538 \\
\hline Eyeballs.... & 0.276 & 0.211 & 0.275 & 0.177 & 0.276 & 0.223 & 0.276 & 0.228 & 0.282 & 2.27 \\
\hline Thyroid........ & 0.017 & 0.14 & 0.014 & 0.018 & 0.017 & 0.015 & 0.0197 & 0.0151 & 0.018 & 0.017 \\
\hline Thymus........ & 0.120 & 0.232 & 0.074 & 0.221 & 0.134 & 0.264 & 0.125 & 0.220 & 0.114 & 0.212 \\
\hline Heart,....... & 0.850 & 0.761 & 0.672 & 0.656 & 0.737 & 0.694 & 0.663 & 0.676 & 0.696 & 0.611 \\
\hline Lungs & 1.917 & 0.851 & 1.588 & 0.945 & 1.900 & 0.982 & 2.047 & 0.911 & 1.929 & 1.208 \\
\hline Liver........... & 9.383 & 9.266 & 6.943 & 8.567 & 7.530 & 7.405 & 6.941 & 7.484 & 7.180 & 8.188 \\
\hline $\begin{array}{l}\text { Spleen.................. } \\
\text { Stomach-intestines }\end{array}$ & 0.910 & 0.633 & 0.794 & 0.537 & 0.751 & 0.611 & 0.633 & 0.534 & 0.502 & 0.659 \\
\hline 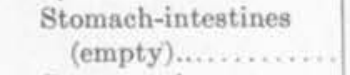 & 7.445 & $3.172^{t}$ & 6.528 & 3.137 & 6.966 & $2.962^{1}$ & 7.191 & $3.244^{1}$ & 7.568 & 3.690 \\
\hline Suprarenals......... & 0.0647 & 0.0525 & 0.0393 & 0.0454 & 0.0485 & 0.0486 & 0.0493 & 0.0548 & 0.0464 & 0.0395 \\
\hline Kidneys.............. & 1.916 & 1.829 & 1.620 & 1.574 & 1.379 & 1.589 & 1.289 & 1.641 & 1.485 & 1.337 \\
\hline Ovaries.................. & 0.496 & 0.652 & 0.436 & 0.614 & 0.053 & 0.064 & 0.530 & 0.615 & 0.455 & 0.492 \\
\hline Pineal.................. & 0.0011 & 0.0012 & 0.0011 & 0.0012 & 0.0011 & 0.0011 & 0.0012 & 0.0011 & 0.0011 & 0.0012 \\
\hline Hypophysis.......... & 0.0093 & 0.0088 & 0.0101 & 0.0088 & 0.0111 & 0.0100 & 0.0101 & 0.0094 & 0.0098 & 0.0084 \\
\hline
\end{tabular}

1 Freed of mesenteries and pancreas. 
TABLE 7

Males: Average absolute weight (in grams) of parts of albino rats grouped according to diet and age when autopsied

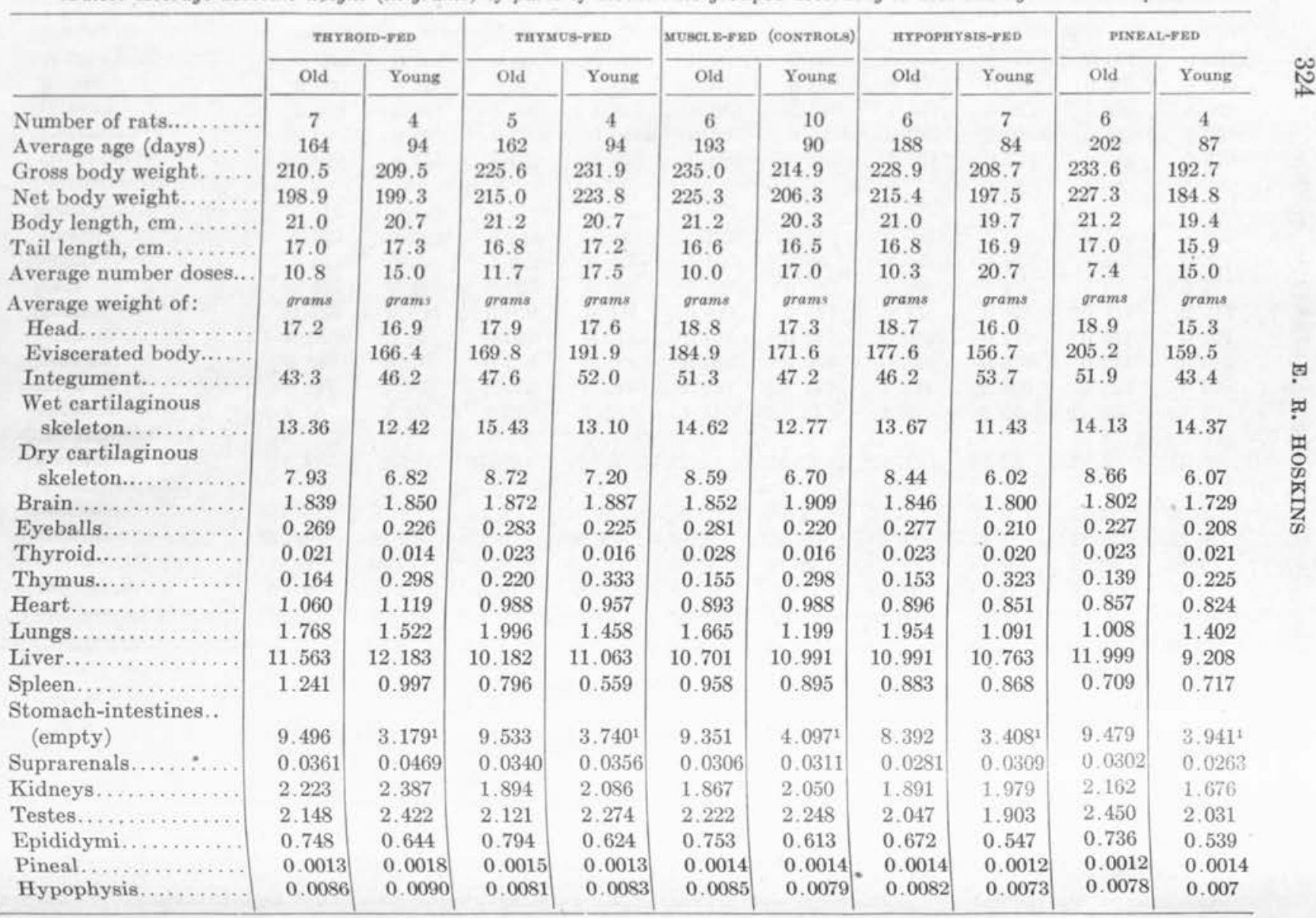


TABLE 8

Females: Average relative (percentage of net body) weight of parts in albino rats grouped according to diet and age when autopsied

\begin{tabular}{|c|c|c|c|c|c|c|c|c|c|c|}
\hline & \multicolumn{2}{|c|}{ THYROID-PED } & \multicolumn{2}{|c|}{ THYMUS-FED } & \multicolumn{2}{|c|}{ MUACLE-VED (CONTHOLSS) } & \multicolumn{2}{|c|}{ HYPOРНYAIA-YBD } & \multicolumn{2}{|c|}{ PINEALFED } \\
\hline & Old & Young & Old & Young & Old & Young & Old & Young. & Gid & Young \\
\hline Number of rats.......... & 5 & 4 & 5 & 6 & 8 & 8 & 6 & 5 & 7 & 5 \\
\hline $\begin{array}{l}\text { Average age (days)...... } \\
\text { Average net body weight }\end{array}$ & 207 & 80.5 & 215.4 & 87.5 & 212.6 & 91.7 & 195.6 & 91.8 & 213.7 & 95.4 \\
\hline 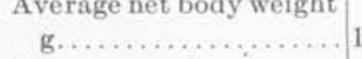 & 169.7 & 140.2 & 151.3 & 149.1 & 165.4 & 152.9 & 151.8 & 142.4 & 164.7 & 138.0 \\
\hline Average number dose .... & $\begin{array}{l}8.6 \\
\text { per cent }\end{array}$ & $\begin{array}{l}12.5 \\
\text { per cent }\end{array}$ & $\begin{array}{l}11.4 \\
\text { per cent }\end{array}$ & $\begin{array}{l}16.7 \\
\text { per cent }\end{array}$ & $\begin{array}{l}11.6 \\
\text { per cent }\end{array}$ & $\begin{array}{l}16.3 \\
\text { per cent }\end{array}$ & $\begin{array}{l}12.8 \\
\text { per cent }\end{array}$ & $\begin{array}{l}12.0 \\
\text { per cent }\end{array}$ & $\begin{array}{l}11.9 \\
\text { per cent }\end{array}$ & $\begin{array}{l}20.0 \\
\text { per cent }\end{array}$ \\
\hline Head................ & 10.56 & 9.64 & 10.61 & 9.34 & 10.28 & 9.54 & 10.28 & 10.13 & 10.00 & 10.02 \\
\hline Eviscerated body..... & 79.26 & 80.87 & 82.08 & 83.15 & 83.72 & 82.51 & 82.44 & 83.69 & 83.33 & 82.02 \\
\hline Integument........... & 21.04 & 22.95 & 21.36 & 22.86 & 21.75 & 22.43 & 20.89 & 22.55 & 21.35 & 21.15 \\
\hline $\begin{array}{l}\text { Wet cartilaginous } \\
\text { skeleton............... } \\
\text { Dry cartilaginous }\end{array}$ & 7.53 & 7.12 & 7.31 & 6.86 & 7.57 & 6.81 & 7.61 & 7.15 & 7.44 & 7.31 \\
\hline skeleton......... & 4.46 & 3.92 & 4.45 & 3.53 & 4.59 & 3.69 & 4.45 & 4.00 & 4.47 & 3.93 \\
\hline Brain .............. & 1.16 & 1.26 & 1.14 & 1.19 & 1.10 & 1.17 & 1.14 & 1.27 & 1.05 & 1.23 \\
\hline Eyeballs............... & 0.187 & 0.152 & 0.186 & 0.149 & 0.171 & 0.141 & 0.188 & 0.162 & 0.172 & 0.164 \\
\hline Thyroid .............. & 0.011 & 0.010 & 0.010 & 0.012 & 0.011 & 0.010 & 0.013 & 0.010 & 0.011 & 0.012 \\
\hline Thymus.............. & 0.080 & 0.161 & 0.061 & 0.157 & 0.070 & 0.172 & 0.079 & 0.184 & 0.071 & 0.154 \\
\hline Heart............. & 0.576 & 0.546 & 0.446 & 0.444 & 0.449 & 0.455 & 4.43 & .0 .477 & 0.428 & 0.442 \\
\hline Lungs........... & 1. 31 & 0.61 & 1.03 & 0.62 & 1.22 & 0.64 & 1.40 & 0.64 & 1.04 & 0.87 \\
\hline Liver............... & 6.24 & 5.98 & 4.63 & 5.71 & 4.58 & 4.89 & 4.13 & 5.30 & 4.36 & 5.87 \\
\hline Spleen ................ & 0.604 & 0.473 & 0.530 & 0.361 & 0.478 & 0.400 & 0.418 & 0.373 & 0.438 & .481 \\
\hline Stomach-intestines & & & & & & & & & & \\
\hline (empty).......... & 4.96 & $2.32^{1}$ & 4.59 & $2.49^{1}$ & 4.24 & $2.07^{1}$ & 4.79 & $2.36^{1}$ & 4.62 & $2.73^{i}$ \\
\hline Suprarenals........... & 0.043 & 0.037 & 0.026 & 0.031 & 0.029 & 0.031 & 0.030 & 0.035 & 0.029 & 0.028 \\
\hline Kidneys............ & 1.30 & 1.32 & 1.06 & 1.06 & 0.92 & 1.04 & 1.05 & 1.09 & 0.91 & 1.05 \\
\hline Ovaries........... & 0.032 & 0.047 & 0.029 & 0.041 & 0.032 & 0.043 & 0.034 & 0.039 & 0.029 & 0.036 \\
\hline Pineal......... & 0.00075 & 0.00084 & 0.00073 & 0.00084 & 0.00067 & 0.00069 & 0.00080 & 0.00078 & 0.00075 & 0.00082 \\
\hline Hypophysis......... & 0.0062 & 0.0063 & 0.0068 & 0.0062 & 0.0067 & 0.0065 & 0.0067 & 0.0067 & 0.0059 & 0.0061 \\
\hline
\end{tabular}

${ }^{1}$ Freed of mesenteries and pancreas. 
TABLE $\theta$

Males: Average relative (percentage of net body) weight of parts in rats grouped according to diet and age when killed

\begin{tabular}{|c|c|c|c|c|c|c|c|c|c|c|}
\hline & \multicolumn{2}{|c|}{ TUYROID-PED } & \multicolumn{2}{|c|}{ THYMUS-red } & \multicolumn{2}{|c|}{ MUBCLE-FED (CONTROLS) } & \multicolumn{2}{|c|}{ HYPOPHYYIS-YED } & \multicolumn{2}{|c|}{ PINEAI-VED } \\
\hline & Old & Young & Old & Young & Old & Young & Old & Young & Old & Young \\
\hline Number of rats........ & 7 & 4 & 5 & 4 & 6 & 10 & 6 & 7 & 6 & 4 \\
\hline $\begin{array}{l}\text { Average age (days)...... } \\
\text { Average net body weight }\end{array}$ & 164 & 93.8 & 161.6 & 94.3 & 192.9 & 90.0 & 188.1 & 84 & 202,1 & 87 \\
\hline $\begin{array}{c}\text { Average net body weight } \\
\text { g...................... }\end{array}$ & 198.9 & 200.3 & 215.0 & 227.5 & 225.3 & 206.3 & 215.4 & 197.5 & 227.0 & 184.8 \\
\hline Average number doses... & $\begin{array}{l}10.8 \\
\text { per cent }\end{array}$ & $\begin{array}{l}15.0 \\
\text { per cent }\end{array}$ & $\begin{array}{l}11.7 \\
\text { per cent }\end{array}$ & $\begin{array}{l}17.5 \\
\text { per cent }\end{array}$ & $\begin{array}{l}10.0 \\
\text { per cent }\end{array}$ & $\begin{array}{l}17.0 \\
\text { per cent }\end{array}$ & $\begin{array}{l}10.3 \\
\text { per cent }\end{array}$ & $\begin{array}{l}20.7 \\
\text { per cent }\end{array}$ & $\begin{array}{l}7.4 \\
\text { per cent }\end{array}$ & $\begin{array}{l}15.0 \\
\text { per cent }\end{array}$ \\
\hline Head......... & 7.37 & 8.44 & 8.38 & 7.89 & 8.40 & 8.34 & 8.84 & 8.13 & 8.46 & 7.89 \\
\hline Eviscerated body..... & 83.1 & 80.74 & 82.85 & 84,24 & 82.24 & 83.20 & 81.81 & 80.07 & 83.46 & 83.52 \\
\hline $\begin{array}{l}\text { Integument............ } \\
\text { Wet cartilaginous }\end{array}$ & 21.33 & 22.86 & 22.05 & 22.95 & 22.48 & 23.02 & 21.65 & 23.35 & 21.94 & 23.51 \\
\hline $\begin{array}{l}\text { skeleton.............. } \\
\text { Dry cartilaginous }\end{array}$ & 6.52 & 6.23 & 7.03 & 5.90 & 6.57 & 6.13 & 6.20 & 5.97 & 6.24 & 6.35 \\
\hline skeleton....... & $4.02^{2}$ & 3.39 & 4.09 & 3.31 & 3.83 & 3.21 & 3.89 & 3.06 & 3.96 & 3.28 \\
\hline Brain............ & 0.93 & 0.93 & 0.88 & 0.86 & 0.84 & 0.94 & 0.88 & 0.91 & 0.80 & 0.94 \\
\hline Eyeb & 0.129 & 0.114 & 0.130 & 0.102 & 0.119 & 0.110 & 0.122 & 0.110 & 0.110 & 0.113 \\
\hline Thyre & 0.010 & 0.007 & 0.011 & 0.007 & 0.013 & 0.008 & 0.011 & 0.010 & 0.012 & 0.011 \\
\hline Thymus............ & 0.73 & 0.155 & 0.104 & 0.153 & 0.072 & 0.051 & 0.072 & 0.167 & 0.62 & 0.167 \\
\hline Heart.............. & 0.545 & 0.555 & 0.465 & 0.486 & 0.401 & 0.472 & 0.425 & 0.435 & 0.435 & 0.446 \\
\hline Lung & 0.89 & 0.76 & 0.94 & 0.65 & 0.74 & 0.60 & 0.92 & 0.55 & 1.01 & 0.79 \\
\hline Live: & 5.88 & 6.16 & 4.76 & 5.04 & 4.87 & 5.16 & 5.23 & 5.47 & 4.13 & 4.95 \\
\hline Spleen.............. & 0.634 & 0.516 & 0.398 & 0.257 & 0.453 & 0.443 & 0.437 & 0.439 & 0.315 & 0.419 \\
\hline $\begin{array}{l}\text { Stomach-intestines } \\
\text { (empty)........... }\end{array}$ & & & & & & & & & & \\
\hline Suprarenals.... & 0.019 & 0.024 & $\begin{array}{l}4.43 \\
0.016\end{array}$ & $\begin{array}{l}1.88^{1} \\
0.016\end{array}$ & $\begin{array}{l}4.18 \\
0.014\end{array}$ & $\begin{array}{l}2.19 \\
0.015\end{array}$ & $\begin{array}{l}4.05 \\
0.013\end{array}$ & $\begin{array}{l}2.07^{1} \\
0.016\end{array}$ & $\begin{array}{l}4.05 \\
0.014\end{array}$ & $\begin{array}{l}2.14^{1} \\
0.016\end{array}$ \\
\hline Kidneys............. & 1.13 & 1.18 & 0.89 & 0.94 & $\begin{array}{l}0.014 \\
0.91\end{array}$ & 1.05 & 0.89 & 1.01 & 0.82 & $\begin{array}{l}0.010 \\
0.90\end{array}$ \\
\hline Testes............... & 1.08 & 1.20 & 0.98 & 1.06 & 1.01 & 1.09 & 0.98 & 0.96 & 0.95 & 1.09 \\
\hline Epididymi............ & 0.38 & 0.31 & 0.37 & 0.28 & 0.34 & 0.36 & 0.32 & 0.28 & 0.35 & 0.29 \\
\hline Pineal................ & 0.0065 & 0.00088 & 0.00070 & 0.00056 & 0.00062 & 0.00069 & 0.00065 & 0.00061 & 0.00052 & 0.00076 \\
\hline Hypophysis........... & 0.044 & 0.0045 & 0.0038 & 0.0037 & 0.0038 & 0.0039 & 0.0037 & 0.0037 & 0.0034 & 0.0040 \\
\hline
\end{tabular}

Freed of mesenteries and panereas.

Group contains 1 rat with an exceptionally heavy skeleton. 
identical conditions. According to Jackson ('13) the coefficient of variability in weight of the thymus at 10 weeks is 22 to 25 .

When compared in absolute weight with Donaldson's Wistar norm for rats of corresponding age (tables 4 and 5) it appears that in my rats the thymus is somewhat lighter, except in the younger male group. The age involution is well known on comparing the older and younger groups (tables 6 to 9), the corresponding body weights in both cases being not greatly different.

b. Thyroid groups. The thymus shows no constant difference in weight that can be attributed to the thyroid diet. It is under weight in the females by an average of 10 per cent, but not in the males.

c. Thymus, hypophysis, and pineal groups. The thymus appears relatively much heavier than normal in the thymusfed older males, but as no corresponding difference is found in the younger males, or in the females, the result is probably due to accidental variations.

\section{Heart (tables 4 to 10)}

a. Controls. In absolute weight, the heart of the older rats in my series (tables 4 and 5 ) is in general in fairly close agreement with the corresponding data in Donaldson's tables, but in my younger males the heart is considerably heavier than Donaldson's norm for rats of corresponding body weight or length. Jackson ('13) also found the normal heart relatively somewhat heavier than would be expected according to Hataj's curve of theoretical growth.

b. Thyroid groups. The heart shows a very marked hypertrophy in rats to which thyroid was fed, excepting 3 old males, in which the dosage was too small to be effective. If calculated by Donaldson's method, the hypertrophy amounts to 24.6 and 16.7 per cent for the older and younger females respectively, and 36 and 15.4 per cent for the corresponding males (table 10).

c. Thymus, hypophysis, and pineal groups. No constant or apparently significant variations appear in the heart in these groups. 
TABLE 10

Thyroid-fed albino rats. Average percentage deviation of organ weight from that of the control rats, compared according to Donaldson's method ('The Rat,' Donaldson '15).

\begin{tabular}{|c|c|c|c|c|}
\hline \multirow{2}{*}{ ORGAN } & \multicolumn{2}{|c|}{ OLDER GROUPS } & \multicolumn{2}{|c|}{ YOUNGER GROUPG } \\
\hline & Females & Males & Females & Males \\
\hline & per cent & per cent & per cent & per cent \\
\hline Brain..... & -3.6 & +0.1 & +0.5 & -5.5 \\
\hline Eyeballs... & +0.5 & -0.1 & +6.8 & -8.5 \\
\hline Heart................ & +24.6 & +36.0 & +16.7 & +15.4 \\
\hline Liver................. & +26.7 & +24.6 & +30.5 & +6.4 \\
\hline Spleen............... & +41.3 & +86.0 & +15.0 & +6.4 \\
\hline Alimentary canal........ & +12.1 & +11.8 & & \\
\hline Suprarenals........... & +16.1 & +38.1 & +14.5 & +36.4 \\
\hline Kidneys........ & +46.3 & +44.4 & +33.0 & +40.4 \\
\hline Ovaries................. & -3.2 & & -3.5 & \\
\hline Testes.................. & & -0.2 & & +9.8 \\
\hline Hypophysis.......... & -11.5 & +21.3 & -8.8 & +18.0 \\
\hline
\end{tabular}

\section{Lungs (tables 4 to 9 )}

a. Controls. The weights of the lungs in the older rats are considerably heavier than those of Donaldson's tables, owing to the prevalence of pulmonary infection in my older rats. The younger rats are in close agreement with the Wistar tables.

b. Thyroid groups. On account of the great variation due to the frequency of lung infection (especially in the older animals), no conclusions can be drawn from the apparent changes in the weight of the lungs in the thyroid-fed groups.

c. Thymus, hypophysis, and pineal groups. There are no differences that are of significance in the weights of the lungs in these groups.

\section{Liver (tables 4 to 10 )}

a. Controls. In absolute weight, the liver averaged somewhat below the corresponding figures in Donaldson's Wistar tables, excepting in the younger males. Jackson ('13) also found the liver normally considerably below the theoretical curve derived by Hatai ('13). The liver is known to vary greatly under different circumstances, however, and is considerably 
influenced in size by diet, etc. One might expect a relatively larger liver in the female, which is said to be more active than the male (Slonaker '12), since exercise has been shown to cause hypertrophy of this organ (Hatai '15). Jackson ('13) found the liver heavier in the male, however, and this is apparently true also for my control animals.

b. Thyroid groups. In the thyroid-fed groups, (tables 8 to 10) the liver appears relatively considerably heavier than in the controls. When compared according to Donaldson's method, the females show an increase in the absolute weight of the liver of 26.7 per cent and 30.5 per cent for the older and younger groups respectively, and the males show a corresponding increase of 24.4 per cent and 6.4 per cent. The apparently small increase in the weight of the liver of the younger males is probably to be explained by the fact that the liver is unusually heavy in the corresponding control group. Even when due allowance for normal variability is made, a hypertrophy of the liver due to thyroid feeding is therefore strongly indicated.

c. Thymus, hypophysis, and pineal groups. In all the younger groups of females the liver averages larger than in the controls, but as no corresponding difference is found in the other groups, the variation is probably not significant.

\section{Spleen (tables 4 to 10)}

a. Controls. As appears by comparing the individual data, the absolute weight of the spleen in the control groups is from 30 per cent to 100 per cent higher than the figures for corresponding animals in Donaldson's Wistar tables. In the latter tables, however, the figures for the spleen are derived from the formula of Hatai ('13) who used data from which the 'enlarged' spleens had been excluded. Whether these tables for the spleen really represent the true norm is therefore questionable, since it is not known whether the 'enlarged' spleens are actually pathological, or represent merely extreme cases of normal variation in size. Jackson (13) found the variability 
of the spleen in the rat very high (coefficient of variation averaged about 35). His relative (percentage) values for the normal spleen (including all specimens) are also somewhat above the curve derived from Hatai's formula (excluding enlarged specimens), but are considerably lower than mine, excepting the old male group (tables 8 and 9 ). It is evident that my control spleens are relatively larger than that which is usually considered normal, but it is impossible to say whether or not this is due to normal variability. A study of individual data shows that the weight of the spleen in most rats varies in the same direction as that of the liver. Dr. Hatai of the Wistar Institute has told me that he also has noted such correlation. This fact is in agreement with the doctrine that the spleen functions in furnishing certain materials to the liver for use in general metabolism. Sweet and Ellis ('15) state that where digestion is interfered with greatly by removal of the external function of the pancreas, the spleen undergoes marked simple atrophy.

b. Thyroid groups (tables 6 to 10). In relative weight where the averages of the thyroid groups are compared with the entire control group it is seen that there is an increase in the weight of the spleen of about 25 per cent. According to Donaldson's method of comparison the increase in absolute weight amounts to 41.3 per cent and 15 per cent in the older and younger female groups, and of 86 per cent and 6.4 per cent in the corresponding male groups (table 10). The apparently small increase shown by the younger group of males is due to an unusually large spleen in the control group, in which the liver was also unusually large (as above mentioned).

c. Thymus, hypophysis, and pineal groups. As might be expected, the spleen in these groups shows considerable variability, but it is probably within the limits of normal variation. There appear decidedly smaller spleens in the thymus-fed male group, but the results are not constant, and of doubtful significance. 


\section{Alimentary canal (tables \& to 10)}

a. Controls. As may be seen in tables 4 and 5 , the absolute weights obtained for the alimentary canal (empty stomach and intestines, plus mesentery and pancreas) average slightly lower than in Donaldson's tables corresponding to the older males and females. In my younger rats, no data for this system are available. The alimentary canal, including the stomach and intestines when freed from the pancreas and mesentery, weighs about 3 grams in the younger female rats (average 13 weeks old) and 4.1 grams in the males of the same age, forming about 2.1 per cent of the net body weight in the former and a little less in the latter (tables 8 and 9 ). The measurements can be made only approximately on account of the difficulty in removing completely the contents of the canal without loss of a part of the mucosa. No data for comparison with the digestive canal without mesentery are available.

b. Thyroid groups. The empty alimentary canal appears heavier in relative weight both in males and females of the older thyroid groups than in the corresponding controls (tables 8 and 9 ). In no case is the difference very large, however, and owing to variability and difficulty in securing exact weights of the empty canal, the difference is of doubtful significance. Compared by Donaldson's method, the increase in weight is about 12 per cent in each older group (table 10).

c. Thymus, hypophysis, and pineal groups. The variations observed in the alimentary canal of these groups (tables 6 to 9) in comparison with the controls are inconstant, and probably within the limits of normal variability and experimental error.

\section{Suprarenal glands (tables 4 to 10 )}

a. Controls. In absolute weight as compared with Donaldson's norms, the suprarenals of my rats (tables 4 and 5) are somewhat light in the case of the males, but correspond more closely in the females.

In relative weight (tables 8 and 9) my data correspond fairly well with the results of Jackson ('13), but the suprarenals of 
my rats have a slightly higher percentage in the females and lower in the males, than in Jackson's older rats of corresponding body weight. The sexual difference in the weight of the suprarenals discovered independently by Jackson ('13) and by Hatai ('13) occurs likewise in my rats.

b. Thyroid groups. As shown in tables 6 to 10 , the thyroidfed animals show a distinct increase in the relative size of the suprarenals in all groups. According to Donaldson's method of comparison, the younger females show an overgrowth in the absolute weight of the suprarenals of 14.5 per cent, the older females of 16.1 per cent, the younger males of 36.4 per cent, and the older males of 38.1 per cent (table 10). This indicates that the reaction of the suprarenals to thyroid treatment is relatively greater in males, in which sex the gland is normally relatively lighter in weight than it is in the females.

c. Thymus, hypophysis, and pineal groups. In all these groups the suprarenal glands do not appear to differ from the controls more than might be expected from the normal variability (tables 6 to 9 ). In the younger pineal-fed female rats, however, the suprarenals average about 9 per cent lighter in weight than in the corresponding controls.

\section{Kidneys (tables 4 to 10)}

a. Controls. As compared with Donaldson's tables, the kidneys in my rats (tables 4 and 5) were somewhat heavier in the younger groups and lighter in the older groups. The differences are not great, however, and may possibly be due to age. My younger rats are larger than is usual at that age. The relative size of the kidney tends to decrease with the less active metabolism of adult life.

In relative (percentage) weight (tables 8 and 9), all the groups are in fairly close agreement with the results obtained by Jackson ('13) for rats of the same age. In two rats of the same sex and same size but of different age, the younger usually has larger
kidneys. 
b. Thyroid groups. The kidneys reacted to the thyroid feeding in a manner similar to that described for the liver, but to a greater extent (tables 6 to 10). According to Donaldson's method of comparison the increase in the absolute weight of the kidneys is as follows: older females 46.3 per cent, younger females 33.0 per cent, older males 44.4 per cent, and younger males 40.4 per cent (table 10).

c. Thymus, hypophysis and pineal groups. As shown in tables 6 to 9 , the kidneys in the various groups fed on thymus, hypophysis and pineal gland show no very constant variations from the controls. The differences are mostly small and are probably due to normal variability. The kidneys of the hypophysis-fed females average 12 per cent heavier than the controls, however, and those of the pineal-fed males average 16 per cent under normal weight.

\section{Ovaries (tables 4, 6, 8 and 10)}

a. Controls. In absolute weight, the ovaries appear considerably heavier for the younger group, and slightly heavier for the older group (table 4) than the corresponding ovaries in Donaldson's tables. In relative (percentage) weight, the ovary in the younger groups similarly exceeds the normal found by Jackson ('13), and is about equal in the older group. The ovaries are normally found to be exceedingly variable in weight. This is to be explained partly on account of varying stages of ovulation, and partly to technical difficulties of dissection (Jackson'13).

b. Thyroid groups. The ovaries in the thyroid groups appear nearly unchanged, the slight differences being very probably due to normal variation.

c. Thymus, hypophysis, and pineal groups. On comparing the relative weights of the ovaries in these groups, no important or constant changes are found (table 8), except in the pinealfed group. In these the ovaries appear considerably under weight, as compared with the controls. The decrease in absolute weight shown by Donaldson's method is 16.7 and 27.0 
per cent for the older and younger groups respectively. Possibly pineal feeding retards growth of ovaries, but on account of their great variability and the comparatively small number of observations, there is considerable doubt as to whether the decrease noted is significant.

\section{Testes (tables 5, 7, 9 and 10)}

a. Controls. In absolute weight, compared with Donaldson's tables, the testes in my rats average slightly lighter (table 5)

In relative (percentage) weight (table 9 ), in comparison with the observations of Jackson ('13) on animals of corresponding weight, the testes in my series appear relatively lighter in the older group and of about the same relative weight in the younger groups. Jackson's data included the epididymis, however, and on this basis, with testis and epididymis combined, both my old and young groups would appear to have heavier organs.

b. Thyroid group. The testes of both sub-groups of the thyroid-fed males (table 9) show a slight increase in relative weight as compared with the entire group of controls. This overgrowth ranges from about 7 per cent in the group of older rats (in part of which the dosage is very small and ineffective)to 13 per cent in the young animals. Calculated by Donaldson's method the older rats are seen to have testes of the same absolute weight as the controls, and the younger rats to have heavier (10 per cent) testes than the corresponding controls. As in the case of the ovaries, however, the testes show considerable normal variability, and conclusions based upon a relatively small number of observations must be carefully guarded.

c. Thymus, hypophysis, and pineal groups. In these groups the testes show no important or constant changes in comparison with the controls, and the differences (e.g., the apparent slight retardation of the testis in pineal-fed) are probably not significant. Microscopic examination of the testis of a thymus-fed rat showed no degeneration, although Hewer ('14) found such condition in rats, some of which were fed but slightly more thymus than some of my rats received. (Mine were fed up to 1.4 grams fresh or 0.15 grams dried thymus on alternate days; hers were fed 1 to 4 grams of the fresh thymus daily.) 


\section{Epididymi (tables 7 and 9 )}

a. Controls. Few data are available for comparison. Jackson ('13) states that after the age of puberty the epididymis weighs about one-third as much as the testis, and in extreme cases one-half. In my series (tables 7 and 9 ) the eipdidymi average about one-fourth as heavy as the testes in the younger $(0.28$ per cent of net body weight), and about one-third as heavy in the older group ( 0.34 per cent of net body weight). Some of the variability in the weight of the epididyinis is due to the difficulty in removing the fat associated with it.

b. Thyroid groups. The epididymi in the thyroid group, like the testes, appear slightly larger than in the control rats (tables 7 and 9). It is doubtful whether they are stimulated in growth by the thyroid treatment, however.

c. Thymus, hypophysis, and pineal groups. In these groups, as was true in regard to the testis, the variations in comparison with the controls are probably not significant.

\section{Pineal body (tables 6 to 9 )}

a. Controls. No attempt has hitherto been made to determine the normal weight of this small organ in a large series of albino rats. Biedl ('13) gives the weight as 0.0020 g., which is considerably higher than the average weights in my series $(0.0011 \mathrm{~g}$. in the females and $0.0013-0.0014 \mathrm{~g}$. in the males, tables 6 and 7 ). The weight values obtained vary greatly on account of the extremely small size of the gland. Relatively (tables 8 and 9) there seems to be no significant difference according to sex or age, although the percentage weight appears to be somewhat less in the animals of greater body weight, and this to some extent is due to age. Recently, from data secured through the kindness of Dr. Donaldson and Dr. Hatai, I note that the values obtained for the pineal body in rats at the Wistar Institute agree fairly closely with mine.

b. Thyroid groups. The pineal body in the thryoid-fed rats (tables 8 and 9) averages in relative weight somewhat heavier in the various groups than in the corresponding controls. The 
difference is not constant in every litter so that, although it is possible that the thyroid medication increases the weight of this organ, the data are insufficient for a final conclusion.

c. Thymus, hypophysis, and pineal groups. On comparing the relative weights of the pineal body in these groups, the results in the case of the thymus-fed and hypophysis-fed are very inconstant. In the pineal-fed, as in the thyroid-fed rats, the pineal body appears usually increased in relative weight. The difference in weight is not constant in every litter, and hence is of doubtful significance, in all of these three groups.

\section{Hypophysis (tables 7 to 10)}

a. Controls. In absolute weight the hypophysis in both male and female rats in my series agree fairly well with Donaldson's tables for rats of corresponding body length or body weight (tables 4 and 5). There is a sexual difference in the weight of this organ, as discovered by Hatai ('13). As seen in tables 8 and 9 , is about 0.0066 per cent in net body weight for the hypophysis the males (not much change according and 0.0039 per cent in Thus the hypophysis, like the suprar to age or body weight). rats relatively much larger in the adult

$b$. Thyroid groups.

with the controls (tables 8 to 10 ), the thyroid-fed animals decrease in relative weight of the In both male groups there is a decided increase in the groups. of the hypophysis. With Donaldson's methose in the weight the decrease in absolute weight in then's method of comparison groups is 11.5 and 8.8 per cent respectively, and younger female in the corresponding males is 21.3 respectively, and the increase These results may be interpreted and 18.0 per cent (table 10). ence in the effect of thyroid feeding indicating a sexual differeffect being most marked in the therefore tends to reduce the normal different thyroid-feeding sexes in the weight of the hypophysis. 


\section{Summary}

a. Comparison of controls with established norms for body weight, body and tail length, and size of organs. In regard to body weight, the control rats used in this investigation as well as the experimental animals can be divided into two groups: (1) an older group ('summer-born') which were born in the summer and early fall; and (2) a younger group ('winter-born') which were born in the winter and spring. The first group maintained about the same size and body weight as the rats of Donaldson ('06) and Jackson ('13). The second group, especially the males, were considerably larger at every stage, and more nearly resembled in growth the selected strong and vigorous litters of rats recently studied by King ('15).

The ratio of tail length to body length is somewhat less in my series than in the norms of Jackson ('15) and those calculated from Donaldson's Wistar tables. That is, my rats were relatively short-tailed.

The variability of growth in body weight, body length and tail length is thus emphasized. Such differences may occur in different 'strains' of rats, especially under different conditions of environment, diet, etc. Experience shows that the average body weight may be considerably increased by unusual eare and liberal feeding. Exercise has also been shown to affect markedly the growth of the body (Slonaker '12) and organs (Hatai '15) of the rat.

As to the absolute weights of the individual organs and parts, the data for the controls in general agree fairly well with those of Donaldson's Wistar tables for corresponding body length and body weight (tables 4 and 5 ). The differences are in most instances no greater than might be expected from normal variability, especially in rats of different strain kept under different environment. In some cases (e.g., thyroid gland, thymus, and alimentary canal) there are differences due to difference in the technique of removing the organs.

In the case of the very rapidly growing rats, it is quite probable that some of the peculiarities (e.g., of skeleton, spleen, liver, 
heart, kidneys) in comparison with older rats of similar body weight may be due to changes with age, independent of body weight. The younger rats with more rapid metabolism may have relatively larger organs. Donaldson has found a close correlation between the water content of the central nervous system and age in the rat. The age involution of the thymus is well known, and Jackson ('13) found indications of correlation with age in the weight of the eyeballs. Similar relations are possible in other organs, although organ weight in general is doubtless more closely correlated with body weight than with age.

In relative (percentage) weights, the organs likewise are in general correspondence with the results of Jackson ('15), the bility to be expected. between the weights. There was noted a marked correlation b. Effects of thyroid feeding. affected the gross body weight of the thyroid diet apparently The 'higher dosage' animals average the rats but very slightly. controls and other groups (charts 3 and 4 ), heavier than the is perhaps too slight to be significant. 3 and 4 ), but the difference thyroid-fed animals be taken into ant. If the loss in fat of the of the remainder of taken into account, an increased weight

The results are not body appears.

roid feeding with small dosatible with the view that by thyproduced (as found by Moussu an increase in body weight is higher dosage a decrease or retardation Schäfer '12), while with duced (Magnus-Levy '95; Moussu' Rooke and McKie '12; Gudernatsch '99, Bircher '10; Carlson, Cotroni '14; Romeis '15). The dech '12, '14, '15; Hewitt' 14; weight reported by most of the decrease or retardation of body is possibly due to the toxic effect mentioned investigators that two thyroid-fed rats apparently large doses. I observed by a single large dose (200 aparently in good health were killed

The eviscerated body and (to of dried thyroid substance. ment of the thyroid-fed fats usually slighter extent) the integutive weight, probably due to loss of fat. 
The organs of the rats which received very little thyroid were not much affectedin weight, but in the rats which received larger doses (see tables 6 to 10 ) several of the organs are evidently hypertrophied. This cannot be interpreted as merely a relative gain, due to loss of body-fat, for the body weight, as above stated, has apparently suffered no loss in the thyroid-fed rats, but possibly a slight gain instead. The organs which show a considerable increase in weight are the heart, liver, spleen, suprarenals and kidneys.

Other organs in which the results are more doubtful, but which seem to be increased in weight to a greater or lesser extent are the hypophysis (male), and alimentary canal, and possibly the skeleton, testes, and epididymi. The increase of this group of organs is uncertain, and in some cases probably due to chance variations.

These results are in general agreement with those of Iscovesco ('13) who (by thyroid extract injections) found hypertrophy of the heart, thyroid gland, suprarenals, kidneys (male), testes, ovaries and uterus. He reports an increase in the weight of these organs of nearly 100 per cent, but no increase in the weight of the liver or female kidneys. My results confirm also the hypertrophy of the suprarenal glands found by Rudinger, Falta and Eppinger ('08), and by Hoskins ('10a). They also confirm to some extent the results of Bircher ('10a) (10b), who found that hyperthyroidism produces enlargement of the heart and thyroid gland, and acceleration of skeletal development. They do not, however, agree with Utterström ('10), who found enlargement of the thymus.

It may be noted further that these results likewise agree with the generally accepted doctrine that hyperthyroidism produces a general acceleration of metabolism. Conditions increasing metabolism would naturally throw a greater burden upon the important viscera, and thus tend to produce in them a hypertrophy. Thus Hatai ('15) has shown that increased exercise in albino rats tends to produce an enlargement of various organs, and his results resemble closely those obtained by me with thyroid feeding. 
c. Effects of thymus feeding. In general, the results of thymus feeding were negative. Neither the body as a whole nor any of the individual parts or organs showed any marked or constant apparent effect, in comparison with the controls. The apparent tendency to decrease in the relative weight of the male spleen is a doubtful exception.

The negative results are in agreement with those of Miss Hewer ('14), except as to the degeneration of the testis; but they do not confirm in the rat the stimulating effect upon body growth obtained by Gudernatsch ('12) ('14) and (in part) by Romeis ('15) in amphibian larvae.

d. Effects of hypophysis feeding. The data in the present experiments show that the weights of the body as a whole and of the various parts and organs of the albino rats in the hypophysis-fed groups were even more closely in agreement with the controls than were the thymus groups. The apparent increase in weight shown by the kidneys and thyroid of the females is probably not significant.

The negative results of the hypophysis feeding in these experiments confirm similar findings as to negative effects upon body weight by Caselli ('00); Sandri (anterior lobe )('09); Hoskins ('11); Aldrich ('12a) ('12b); Schäfer ('12); Lewis and Miller ('13), and Gudernatsch ('14). On the other hand they do not agree with Schäfer ('09) and Goetsch ('16) who from very few data reported growth stimulated by feeding anterior lobe of hypophysis, nor with the following who obtained retardation of growth (especially skeletal) by hypophysis feeding: Thompson and Johnston ('05); Etienne and Parisot ('08); Sandri ('07) ('09) (posterior lobe); Cushing and Goetsch (cited by Cushing '12); Wulzen ('14), and Pearl ('16) (anterior lobe). My results likewise disagree with Hallion and Alquier ('08) who obtained hypertrophy of the suprarenal glands, and with Wulzen ('14) who found accelerated involution of the thymus. It may be noted, however, that my dosage was comparatively small subtoxic, and this might account for the negative results.

e. Effects of pineal feeding. The pineal groups also agree fairly closely in weight with the control animals, both as to the 
body as a whole and in the various organs and parts. Several minor differences are to be noted, but all are perhaps within the limit of normal variability. The testes, kidneys (male), ovaries, and suprarenals show a decrease in weight which is of doubtful significance, as (except in the case of the ovaries) it is not constant in every litter. My results agree with Priore ('15) who obtained negative results on body growth by injection of pineal extracts. They disagree, however, with those of Dana and Berkeley ('14) and McCord ('14, '15) who obtained an acceleration in body growth by feeding pineal substance.

\section{CONCLUSIONS}

Some of the principal results of the present investigation may be summed up briefly as follows:

1. The normal growth of the albino rat varies materially, not only in different 'strains' and under different conditions of environment, but even among litters when all conditions are as nearly constant as possible. It is therefore not sufficient to rely upon the established norms of growth for comparison, but in all cases experimental and control animals should be selected of the same sex and from the same litter or litters.

2 . In the case of rats with unusually rapid (or slow) growth, in addition to comparison with (older or younger) rats of corresponding size and weight, due regard for possible changes correlated with age must be observed. Such changes have previously been noted in the water content of nervous system (Donaldson), weight of the thymus (Hatai), and probably the weight of the eyeballs (Jackson). Indications of similar agechanges (independent of body weight) are found in the skeleton, liver, kidneys, heart and spleen. Compared with animals of the usual age at a given body weight, the skeleton seems to be relatively heavy in older animals, and the other organs are apparently heavier in younger rapidly growing animals.

3 . There is apparently no sexual difference in the relative weight of the pineal body, such as has been found in the suprarenal glands (Jackson '13, Hatai '13) and the hypophysis (Hatai '13). 
4. Thyroid feeding (in sub-toxic doses) causes little or no change in body weight in growing rats. There is possibly a slight stimulation in growth of the body as a whole, balanced by a decrease in the amount of free fat in the body. There is a slight loss in the relative weights of the eviscerated body and the integument, probably due to loss of body-fat.

5. Thyroid feeding produces a decided hypertrophy of the heart, liver, spleen, kidneys and suprarenal glands (especially in males). It apparently causes also a somewhat less extensive and more uncertain increase in the weights of the alimentary canal and hypophysis (male) and possibly in the skeleton, testes and epididymi, and a decrease in the weight of the hypophysis of females.

6. Thymus feeding (with the dosage employed) has no apparent effect upon the growth rate of the body of albino rats. No constant or important effect upon any of the individual organs or parts was observed. The testis showed no degenerative or other changes.

7. Hypophysis feeding (with the sub-toxic dosage employed) produces no marked or constant effect upon the growth rate of the body or organs of albino rats.

8. Pineal feeding likewise produces no apparent changes in the weight of the body or organs of the albino rat, beyond differences probably within the limits of normal variation. 


\section{LITERATURE CITED}

For a complete review of the literature of the ductless glands, published prior to 1913 , the reader is referred to 'Innere Sekretion,' Biedl ('13).

AMDEKHALDEN, E. 1915 Studien uber die von einzelnen Organen hervorgebrachten Substanzen mit specifischer Wirkung. I. Mittheilung. Archiv. f. d. ges. Physiol., Bd. 162, S. 99.

Aldrich, T. B. 1912 a On feeding young pups the anterior lobe of the pituitary gland. Am. Jour. Physiol., vol. 30.

$1912 \mathrm{~b}$ On feeding young white rats the posterior and anterior parts of the pituitary gland. Am. Jour. Physiol., vol. 31.

BAsch, K. 1913 Beiträge zur Physiologie und Pathologie der Thymus. Zeit. f. exp. Path. u. Therap., Bd. 12.

BEнкиLex, W, N. 1914 The use of pineal glands in the treatment of certain classes of defective children. Med. Rec. (N. Y.), vol. 85.

Bredi, A. 1913 Innere Sekretion. Aufl. 2, Berlin.

Brвcher, E. 1910 a Experimenteller Beitrag zum Kopfhuz. Med. Klinik., Bd. 10 .

1910 b Zur Wirkung der Thyreodintabletten auf das Knocheņwachstum. Arch. f. klin. Chir., Bd. 91.

Cartson, A. J., Rooks, J. R., ANd McKrE, J. F. 1912 Attempts to produce experimental hyperthyroidism in mammals and birds. Amer. Jour. Physiol., vol. 30.

Casellu, A. 1900 Influenza della funzione dell'ipofisi sulla sviluppo dell' organisimo; nota preventiva sulla fisiopatologia della ghiandola pituitaria. Riv, sper. di fren., T. 37.

Cerletti, U. 1907 Effets des injections de suc d'hypophyse sur l'sceroissement somatique. Arch. ital. de Biol, T. 47.

Cotroni, G. 1914 Première contrib. expér, à l'étude des organs dans la croissance et dans la metamorphose des amphib. anoures. Arch. ital. de Biol., T. 61 .

Crowe, S. J., Cushing, H., and Homans, J. 1910 Experimental Hypophysectomy. Bull. Johns Hopkins Hosp., vol. 21.

Cushivg, H. 1909 The hypophysis cerebri. Jour. Amer. Med. Assn. vol. 53. 1912 The pituitary body and its disorders. Philadelphia.

Conninghas, R. H. 1898 Experimental thyroidism. Jour. Exp. Med., vol. 3.

DANA AND BERKELEY 1913 Functions of the pineal gland. Med. Rec. (N. Y.), vol. 83 .

DANDy, W. E. 1915 Extirpation of the pineal body. Jour. Exp. Med., vol. 22.

Deltule, 1909 L'hypophyse et la modifications hypophysaire. Paris. (Cited by Biedl '13).

Donaldson, H. 1906 Comparison of the white rat with man in regard to growth of the entire body. Boas Memorial Volume, N. Y.

1908 A comparison of the albino rat with man in respect to the growth of the brain and of the spinal cord. Jour. Comp. Neur., vol. 18.

1915 The Rat. Reference tables and data. Wistar Memoirs No. 6, Philadelphia. 
Etienne, G., ex Parisot, J. 1908 Action sur l'appareil cardio-vasculaire des injections répétés d'extrait d'hypophyse. Arch. med. expér., vol. 20.

Farrant, R. 1913 Hyperthyroidism; its experimental production in mammals. British Med. Jour,, vol. 2.

Foderd, F. A., ET Prtrad, L. 1909 Studii sull hypophysis cerebri. Gaz. di Med. e. Chir., T. 8.

Franchini, G. 1910 Die Funktion der Hypophyse und die Wirkungen der Injektion ihres Extraktes bei Tieren. Berl. Klin. Woch. No. 14-16.

Gebele, 1911 Ueber experimentelle Versuche mit Basedow-Thymus. Beitr. Klin. Chir., Bd. 76 (Cited by Matti '12).

Gozтsch, E. 1916 The influence of pituitary feeding upon growth and development. Bull. Johns Hopkins Hosp., vol. 27, no. 300.

Goetsch and Cushing, (Unpublished experiments on hypophysis cited by Cushing '12).

Gudernatsch, J. F. 1912 Feeding experiments on Tadpoles. I. Archiv. f. Entw., Bd. 35.

1914 Feeding experiments on tadpoles. II. Am. Jour. Anat. vol. 15. 1915 Feeding experiments on rats (with thyroid). Amer. Jour Physiol., vol. 34 .

Haluion, L., et Alquier, L. 1908 Modifications histologique des glandes a sécrétion interne par ingestion prolongée d'extrait d'hypophyse. C. R. Soc. Biol. Paris, T. 64 .

HAтsI, S. 1913 On the weight of the abdominal and thoracic viscera, sex glands, ductless glands and eyeballs of the albino rat according to body weight. Am. Jour. Anat., vol. 15.

1914 On the weight of the thymus of the albino rat according to age. Am. Jour. Anat., vol. 16.

1915 On the influence of exercise on the growth of organs in the albino rat. Anat. Rec., vol. 9.

HEwrR, E. E. 1914 Effect of thymus feeding on the activity of the reproductive organs in the rat. Jour. Physiol., vol. 47.

НвwгтT, J. A. 1914 The influence on metabolism of administration of anterior lobe of pituitary. Quart. Jour. Exp. Physiol., vol. 7.

Hoskins, E. R. 1916 On the growth of the albino rat as affeeted by environment and by feeding various ductless glands (thyroid, thymus, hypophysis and pineal). Proc. Amer. Assn. Anatomists. Anat. Rec., vol. 10 , no. 3 .

Hoskins, R. G. 1910 a Thyroid secretion as a factor in adrenal activity. Jour. Amer. Med. Assn., vol. 55.

1910 b Congenital thyroidism. Amer. Jour. Physiol., vol. 26.

1911 The interrelation of the organs of internal secretion. I. The thyroid. Amer. Jour. Med. Sc.

Iscovesco, H. 1913 Action physiologique en particulaire sur la eroissance d'un lipoid (11 Ba) extrait de la thyroide. C. R. Soc. Biol. Paris, T. 75 .

JACKson, C. M. 1913 Postnatal growth and variability of the body and of the various organs of the albino rat. Am. Jour. Anat., vol. 15. 
1915 a Effects of inanition upon the relative weights of the various organs of albino rats. Am. Jour. Anat., vol, 18.

$1915 \mathrm{~b}$ Changes in the relative weights of various parts, systems and organs of young albino rats held at constant body-weight by underfeeding for various periods. Jour. Exp. Zoöl., vol. 19.

JACKSON AND LOWREY 1912 On the relative growth of the component parts and systems of the albino rat. Anat. Rec., vol. 6.

KING, HeLEN DEAN 1915 The growth and variability in the body weight of the albino rat. Anat. Rec., vol. 9.

Kosturvy, S. 1910 Ueber chronische Thyreotoxikosen. Mitt. a. d. Grenzgeb. d. Med. und Chir, Bd. 21.

LENHART, C. H. 1915 The influence upon tadpoles of feeding dessicated thyroid gland in variable amounts and of variable iodine contents. Jour. Exp. Med., vol. 22.

Lewis, D. D., AND Miller, J. L. 1913 The relation of the hypophysis to growth. Arch. Int. Med., vol. 2. (Also reported in original communications, Eighth Internat. Congress of Applied Chemistry, vol. XIX, p. 231.)

Lrvingston, A. E. 1914 Effect of thyreoidectomy followed by thyreoid feeding on the weight of the pituitary in rabbits. Proc. Soc. Exp. Biol. and Med., vol. 11.

McCond, C. P. 1914 The pineal gland, etc. Jour. Amer. Med. Assn., vol. 63. 1915 The pineal gland in relation to somatic, sexual and mental development. Jour. Amer. Med. Assn., vol. 65.

MAgus-Levy, A. 1895 Ueber den respiratorischen Gaswechsel unter den Einfluss der Thyreoidea, u. s. w. Berl. klin. Woch., Bd. 30.

Matт, H. 1912 Physiologie und Pathologie der Thymusdrüse. Ergeb. d. In. Med. u. Kinderheilk., Bd. 10.

Moussu, 1899 Influence d l'alimentation thyroidienne sur la croissance regulière. C. R. Soc. Biol. Paris, T. 51.

Morse, M. 1915 Effective principle in thyroid accelerating involution in frog larvae. Jour. Biol. Chem., vol. 19.

Paton, D. N. 1913 Regulators of Metabolism. London.

Paulesco, N. C. 1908 L'hypophyse du cerveau. Vigot Frères, Paris.

PeArl, RAymond 1916 On the effects of feeding pituitary body (anterior lobe) substance and corpus luteum substance to growing chicks. Proc. Nat. Acad. Sci., vol. 2, no. 1.

Priore, N. Del. 1915 Modifications dans la pression sanguine et dans l'accroissement somatique des lapins, a la suite d'injections d'extrait de glande pinéale. Arch. ital. de Biol., T. 63.

RoBertson, T. B. 1916 Experimental studies on growth. III. The influence of the anterior lobe of the pituitary body upon the growth of white mice. Jour. Biol, Chem, vol. 24.

1916 The effects of tethalin. Acceleration in recovery of weight lost during inanition and in the heading of wounds. Jour. Am. Med. Assn., vol. 64 .

Romers, B. 1915 Experimentelle Untersuchungen über Wirkung inner-sekretorische Organe. II. Der Einfluss von Thyreoidea-und ThymusFüterung auf das Wachstum, die Entwicklung und die Regeneration von Anurenlarven. Arch. f. Entwicklungsmechanik, Bd. 41. 
Rudinger, C., Falta, W., and Eppinger, H. 1908 Ueber die Wechselwirkung der Drüsen mit innerer Sekretion. Zeit. klin. Med., Bd. 66.

SALKIND, J. 1915 Contributions histologique a la biologie comparée du thymus. Arch. de Zool. expér. et generale, T. 55.

SANDR1, O. 1909 Contributions à l'anatomie et à la physiologie de Phypophyse. Arch. ital. de Biol., T. 51. (Cf. also Riv. d. patol. nerv. d ment., T.12, 1907).

Scräger, E. A. 1909 The functions of the pituitary body. Proc. Roy. Soc. London, vol. $81 \mathrm{~B}$.

1912 Effects upon the growth and metabolism of the addition of small amounts of ox pituitary and thyreoid to normal diet of white rats. Quart. Jour. Exp. Physiol., vol. 5.

SLONAKER, J. R. 1912 Normal activity of the albino rat from birth to natural death. Jour, Animal Behavior, vol. 2.

Sot., U. 1907 Comment se comportent les testicules chez les animaux privés de thymus. Arch. ital. de Biol., Tome 47.

1910 Modifications du development des os chez les animaux privés de thymus. Arch. ital. de Biol., T. 52.

STockard, C. R. 1913 The effect on the offspring of intoxicating the male parent and the transmission of the defects to the subsequent generations. Am. Natur., vol. 47.

SweEr, J. E., AND Ell.rs. J. W. 1915 The influence upon the spleen and thyroid of the complete removal of the external function of the pancreas. Jour. Exp. Med., vol. 22.

Thompson, W. H., AND Jornston 1905 Note on the effects of pituitary feeding. Jour. Physiol., vol. 33.

UTTERström 1910 Contribution à l'étude des effets de l'hyperthyroidisation. Arch. de Med. Exp., T. 22.

VINCENT, S. 1912 Internal secretion and the ductless glands. London.

Watson, C. 1906 The influence of diet on growth and nutrition. Jour. Physiol., vol. 34 .

West, P. A. 1914 Notes on a sheep thyreoid experiment with frog tadpoles. Science, vol. 39 . Wulzes, R. 1914 Relation of the pituitary to growth. Amer. Jour. Physiol.,
vol. 11. 